\title{
Advances in vaccine delivery systems against viral infectious diseases
}

\author{
Dongyoon $\mathrm{Kim}^{1} \cdot$ Yina $\mathrm{Wu}^{1} \cdot$ Young Bong $\mathrm{Kim}^{2} \cdot$ Yu-Kyoung $\mathrm{Oh}^{1}$
}

Accepted: 9 February 2021 / Published online: 10 March 2021

(c) Controlled Release Society 2021

\begin{abstract}
Although vaccines are available for many infectious diseases, there are still unresolved infectious diseases that threaten global public health. In particular, the rapid spread of unpredictable, highly contagious viruses has recorded numerous infection cases and deaths, and has changed our lives socially or economically through social distancing and wearing masks. The pandemics of unpredictable, highly contagious viruses increase the ever-high social need for rapid vaccine development. Nanotechnologies may hold promise and expedite the development of vaccines against newly emerging infectious viruses. As potential nanoplatforms for delivering antigens to immune cells, delivery systems based on lipids, polymers, proteins, and inorganic nanomaterials have been studied. These nanoplatforms have been tested as a means to deliver vaccines not as a whole, but in the form of protein subunits or as DNA or mRNA sequences encoding the antigen proteins of viruses. This review covers the current status of nanomaterial-based delivery systems for viral antigens, with highlights on nanovaccines against recently emerging infectious viruses, such as severe acute respiratory syndrome coronavirus-2, Middle East respiratory syndrome coronavirus, and Zika virus.
\end{abstract}

Keywords Vaccine delivery systems $\cdot$ Nanotechnology $\cdot$ Viral infectious diseases $\cdot$ Severe acute respiratory syndrome coronavirus-2

\section{Introduction}

The recent outbreaks of various infectious diseases have emphasized the social need for the rapid development of vaccines. The continuous outbreaks of viruses such as severe acute respiratory syndrome-related coronavirus-2 (SARS-CoV-2), Middle East respiratory syndrome coronavirus (MERS-CoV), Ebola, and Zika have put the world in peril against infectious disease. In 2020 , the unprecedently severe pandemic of coronavirus disease 2019 (COVID-19) greatly impacted social activities and the global economy [1]. From a social point of view, adequate intervention in advance and efforts to prevent the spread of disease are more efficient than developing follow-up therapeutics. From an economic perspective, the enormous cost and time

Dongyoon Kim and Yina Wu equally contributed.

Yu-Kyoung Oh

ohyk@snu.ac.kr

1 College of Pharmacy and Research Institute of Pharmaceutical Sciences, Seoul National University, Seoul 08826, Republic of Korea

2 Department of Bio-Medical Science and Engineering, Konkuk University, Seoul 05029, Republic of Korea spent treating a disease would be saved if vaccines were available to control the spread of viral infection [2]. In order to cope with outbreaks of new infectious diseases, we must become able to quickly develop vaccines [3].

Since the first smallpox vaccine was developed in 1798 , conventional vaccinations have mostly relied on live attenuated or inactivated pathogens. A live attenuated vaccine exhibits reduced virulence of the pathogen under laboratory conditions, but the pathogen is still alive and the vaccine contains whole bacteria or viruses that are to be recognized by the human immune system [4]. An inactivated vaccine also includes the whole microorganism, but in this case, the pathogen has been killed by chemical or heat treatment [5]. These conventional vaccine types are generally effective, but they have the potential to raise safety concerns.

Several types of vaccines have been developed to overcome these safety issues and improve vaccine efficacy. To address the safety issues, researchers developed the subunit vaccine, which comprised a purified antigenic piece of the pathogen [6]. As the subunit vaccine does not contain whole pathogens, there is no risk of inducing infection; such vaccines are therefore much safer than previous types [7]. In 
addition, recombinant vaccines were developed as the nextgeneration vaccines to induce immunity against infections [8]. For effective immunogenicity, protein vaccines need to be endocytosed by antigen-presenting cells.

Recently, nucleic acid vaccines, such as DNA and RNA vaccines, have emerged [9]. Nucleic acid vaccines have attracted a great deal of attention because of their ability to induce both humoral and cellular immune responses [10]. Due to their ease of design and manufacturing and their good stability during storage, DNA vaccines offer advantages over traditional vaccines [11]. Similarly, RNA vaccines, which cause antigen proteins to be expressed in the cytoplasm, have attracted the interest of vaccine developers: they can induce potent immune response and can be more rapidly and easily manufactured compared with the conventional live-attenuated or killed vaccines [10, 12].

Despite having various advantages over conventional vaccines, nucleic acid vaccines suffer from low immunogenicity [13]. This major drawback of nucleic acid vaccines reflects their limited delivery to antigen-presenting cells (e.g., dendritic cells) and insufficient expression of target antigens. Thus, for nucleic acid vaccines to succeed, researchers should develop delivery systems that can enhance the uptake and expression of antigen-encoding nucleic acids at antigenpresenting cells.

To reach their full potential, vaccines should be delivered intact to the location at which they are intended to activate the immune system. In this regard, nanotechnology holds promise for the development of vaccine antigen delivery systems and immune-stimulating adjuvants [14]. This review will cover various vaccine delivery systems and the current status of nanotechnology-based vaccines for infectious diseases. As vaccine antigen types, subunit protein, DNA, and RNA vaccines will be highlighted. As vaccine nanocarriers, liposomes, polymeric micelles, self-assembled peptide, and proteins nanoparticles will be reviewed for each antigen type.

\section{Nanotechnology for delivery of viral vaccines}

Nanotechnology has been used to deliver various vaccine antigens, including DNA, RNA, and protein subunit vaccines via different routes. Using a proper administration route for vaccination is a critical factor that can impact vaccine efficacy and patient compliance. To induce desirable vaccine efficacy, the vaccine should be distributed from the administered site to suitable immune organs with high populations of antigen-presenting cells. As the types and extent of induced immune responses can differ according to the vaccine-administered site, routes of vaccination should be carefully considered. The types and administration routes of various nanotechnology-based vaccines are listed in Table 1 .

\section{Delivery systems for nucleic acid vaccines against viral infectious diseases}

Cationic liposomes [15], polymeric nanoparticles [16], inorganic gold nanorods [17], peptide nanofibers [18], and carbon nanoparticles [19] have been studied for the delivery of DNA vaccines against viral infectious diseases. These delivery systems aimed to protect the DNA vaccines from enzymatic degradation in the extracellular environment, and to facilitate intracellular delivery. As viral vaccine antigens, DNA encoding human immunodeficiency virus 1 envelope (HIV-1 env) protein pg 145 and influenza virus $\mathrm{H} 1 \mathrm{~N} 1$ hemagglutinin have been delivered via various routes of administration. The examples of DNA delivery systems are illustrated in Fig. 1.

mRNA vaccines have several merits over DNA vaccines; for example, they carry no risk of integrating into the host genome and can induce transient antigen expression without causing genetic transformation [20]. From the perspective of intracellular transport to the target site, mRNA vaccines have one less physical barrier. Unlike DNA vaccines, which need to pass through the nuclear membrane and reach the nucleus to undergo transcription, mRNA vaccines need only to reach the cytoplasm, where they can meet ribosomes for translation. However, due to the low expression levels achieved by exogenous mRNA in the host cells, large mRNA doses are needed to achieve a therapeutic effect. Efficient delivery may reduce the dose of mRNA vaccine needed to exert immunogenicity.

For delivery of mRNA vaccines against viral diseases such as HIV and influenza virus, lipid nanoparticles, polymeric nanoparticles, cell-penetrating peptides, and cationic polysaccharides have been investigated. As routes of administration, intramuscular, intradermal, and subcutaneous routes have been used. Examples of mRNA delivery systems are illustrated in Fig. 1.

\section{Lipid-based systems for delivery of nucleic acid viral vaccines}

Lipid-based systems have been intensively studied to enhance the cellular delivery of nucleic acid vaccines. Due to the amphiphilic characteristics of lipids with hydrophilic head groups and hydrophobic tails, lipids can self-assemble to form bilayer nanostructures like liposomes. In particular, positively charged lipids can form complexes with anionic nucleic acid via charge-charge interaction. The compositions of lipid components confer liposomes to carry versatile cargoes. 
Table 1 Nanotechnologies used for delivery of vaccines against viral infectious diseases

\begin{tabular}{|c|c|c|c|c|c|c|}
\hline Vaccine type & Target virus & Antigen & Formulation & Route & Animal model & Reference \\
\hline \multirow[t]{13}{*}{ Nucleic acid } & HIV & HIV-1 Env encoding DNA & $\begin{array}{l}\text { Mannosylated zwitterionic-based } \\
\text { cationic liposome }\end{array}$ & Intramuscular & $\mathrm{Balb} / \mathrm{c}$ mice & 15 \\
\hline & Influenza virus & $\begin{array}{l}\text { H1N1 hemagglutinin } \\
\text { encoding RNA }\end{array}$ & Mannosylated lipid nanoparticles & $\begin{array}{l}\text { Intramuscular, } \\
\text { intradermal }\end{array}$ & $\mathrm{Balb} / \mathrm{c}$ mice & 21 \\
\hline & Influenza virus & $\begin{array}{l}\text { Influenza hemagglutinin } \\
\text { encoding RNA }\end{array}$ & Lipid nanoparticle & Intradermal & Balb/c mice & 20 \\
\hline & HIV & $\begin{array}{l}\text { Anti-HIV-1 antibody } \\
\text { encoding RNA }\end{array}$ & Lipid nanoparticle & Intravenous & $\mathrm{Balb} / \mathrm{c}$ mice & 26 \\
\hline & Influenza virus & $\begin{array}{l}\text { H1N1 hemagglutinin } \\
\text { encoding DNA }\end{array}$ & PLGA/PEI nanoparticles & $\begin{array}{l}\text { Microneedle } \\
\text { patch }\end{array}$ & $\mathrm{Balb} / \mathrm{c}$ mice & 16 \\
\hline & Influenza virus & $\begin{array}{l}\text { Influenza hemagglutinin } \\
\text { encoding RNA }\end{array}$ & Dendrimer nanoparticle & Intramuscular & $\mathrm{Balb} / \mathrm{c}$ mice & 27 \\
\hline & Influenza virus & $\begin{array}{l}\text { Influenza hemagglutinin } \\
\text { encoding RNA }\end{array}$ & $\begin{array}{l}\text { Poly(CBA-co-4-amino-1-butanol) } \\
\text { polymer-based nanoparticles }\end{array}$ & $\begin{array}{l}\text { Intramuscular, } \\
\text { intradermal }\end{array}$ & $\mathrm{Balb} / \mathrm{c}$ mice & 28 \\
\hline & Influenza virus & $\begin{array}{l}\text { Influenza hemagglutinin or } \\
\text { nucleoprotein encoding } \\
\text { RNA }\end{array}$ & Chitosan-based nanogel & Subcutaneous & $\mathrm{Balb} / \mathrm{c}$ mice & 29 \\
\hline & HIV & HIV-1 gag encoding RNA & $\begin{array}{l}\text { Cationic nanomicelles based on } \\
\text { PEI-stearic acid copolymer }\end{array}$ & Subcutaneous & $\mathrm{Balb} / \mathrm{c}$ mice & 30 \\
\hline & HIV & HIV-1 gag encoding RNA & $\begin{array}{l}\text { PLA-cell penetrating peptide } \\
\text { complex }\end{array}$ & - & - & 31 \\
\hline & HIV & HIV-1 Env encoding DNA & $\begin{array}{l}\text { Peptide-based nanofibrous } \\
\text { hydrogels }\end{array}$ & $\begin{array}{l}\text { Intramuscular, } \\
\text { intradermal, } \\
\text { subcutaneous }\end{array}$ & $\mathrm{Balb} / \mathrm{c}$ mice & 18 \\
\hline & HIV & HIV-1 Env encoding DNA & Surface-engineered gold nanorods & Intradermal & $\mathrm{Balb} / \mathrm{c}$ mice & 17 \\
\hline & HIV & HIV-1 Env encoding DNA & Virus-like fullerenol nanoparticles & Intradermal & $\mathrm{Balb} / \mathrm{c}$ mice & 19 \\
\hline \multirow[t]{8}{*}{ Protein } & Influenza virus & H1N1 nucleoprotein & $\begin{array}{l}\text { Viral-mimetic polymeric nano- } \\
\text { particle }\end{array}$ & Intranasal & C57BL/6 mice & 36 \\
\hline & Hepatitis B virus & Hepatitis B surface antigen & $\begin{array}{l}\text { PLA modified with didodecyldi- } \\
\text { methylammonium bromide }\end{array}$ & Intramuscular & Balb/c mice & 37 \\
\hline & Influenza virus & Influenza matrix protein 2 & Ferritin nanoparticle & Intranasal & Balb/c mice & 38 \\
\hline & Influenza virus & Influenza matrix protein 2 & $\begin{array}{l}\text { Double-layered protein nanopar- } \\
\text { ticles }\end{array}$ & Intramuscular & Balb/c mice & 39 \\
\hline & Influenza virus & $\begin{array}{l}\text { Globular head domain of } \\
\text { the hemagglutinin }\end{array}$ & P22 VLPs & Intratracheal & C57BL/6 mice & 45 \\
\hline & $\begin{array}{l}\text { Lassa mammarenavirus } \\
\text { (LASV) }\end{array}$ & $\begin{array}{l}\text { LASV envelope surface } \\
\text { glycoprotein }\end{array}$ & Mammalian cell-derived VLPs & Intramuscular & Rabbit & 46 \\
\hline & Influenza virus & $\begin{array}{l}\text { Influenza A hemagglutinin } \\
\text { peptides }\end{array}$ & Plant-derived VLPs & - & - & 48 \\
\hline & $\begin{array}{l}\text { Avian infectious bron- } \\
\text { chitis virus }\end{array}$ & $\begin{array}{l}\text { Avian coronavirus spike } \\
\text { protein }\end{array}$ & Gold nanoparticle & Intramuscular & $\mathrm{BALB} / \mathrm{c}$ mice & 50 \\
\hline
\end{tabular}

Mannosylated cationic liposomes have been studied for the delivery of DNA and RNA vaccines encoding viral antigens [15, 21]. Mannose receptors are known to be overexpressed on the surfaces of antigen-presenting cells [22]. Taking advantage of this mannose receptor overexpression, researchers have modified nanomaterials with mannose ligand. In one study, a pegylated lipid derivative of mannose was used to modify cancer cell membranecoated poly (lactic-co-glycolic acid) (PLGA) nanoparticles containing the toll-like receptor 7 agonist, imiquimod [23]. In the study, the cellular uptake of mannose containing nanoparticles by bone marrow-derived dendritic cells was enhanced compared with that of nanoparticles lacking mannose. In another study, mannose-modified alginate nanoparticles were used for the targeted delivery of ovalbumin to dendritic cells and inhibition of tumor growth in mice [24]. The intracellular uptake of mannose-modified nanoparticle-delivered ovalbumin by bone marrow-derived dendritic cells was 3-fold higher than that observed in the free ovalbumin-treated group.

Zwitterionic lipid (distearoyl phosphoethanolaminepolycarboxy-betaine)-modified cationic liposomes were designed for electrostatic complexation with a negatively charged HIV DNA vaccine encoding HIV-1 env [15]. 
a

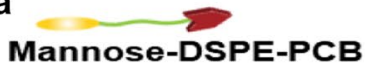

Mannose-DSPE-PCB

DSPE-PCB

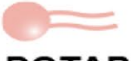

DOTAP

XIIDUDIID

HIV DNA plasmid Env b

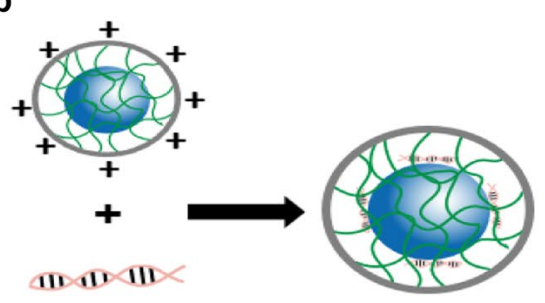

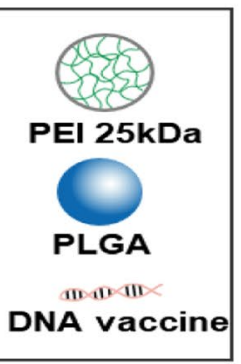

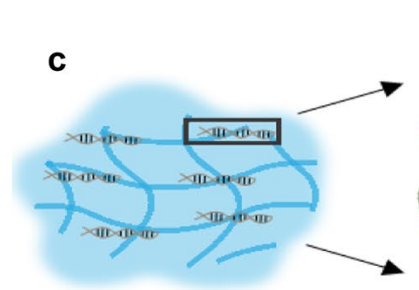

Peptide-based nanofibrous hydrogel

e
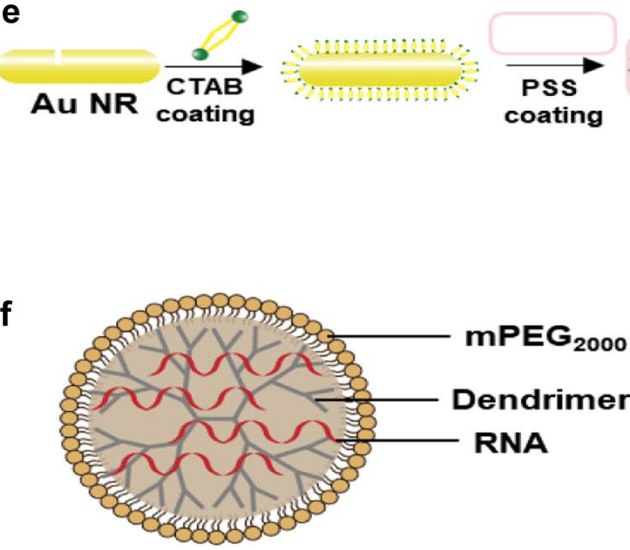

Modified dendrimer NP vaccine
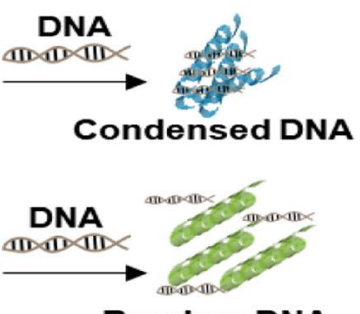

Random DNA d
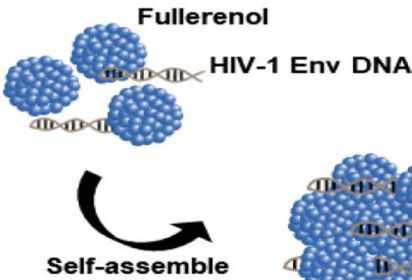
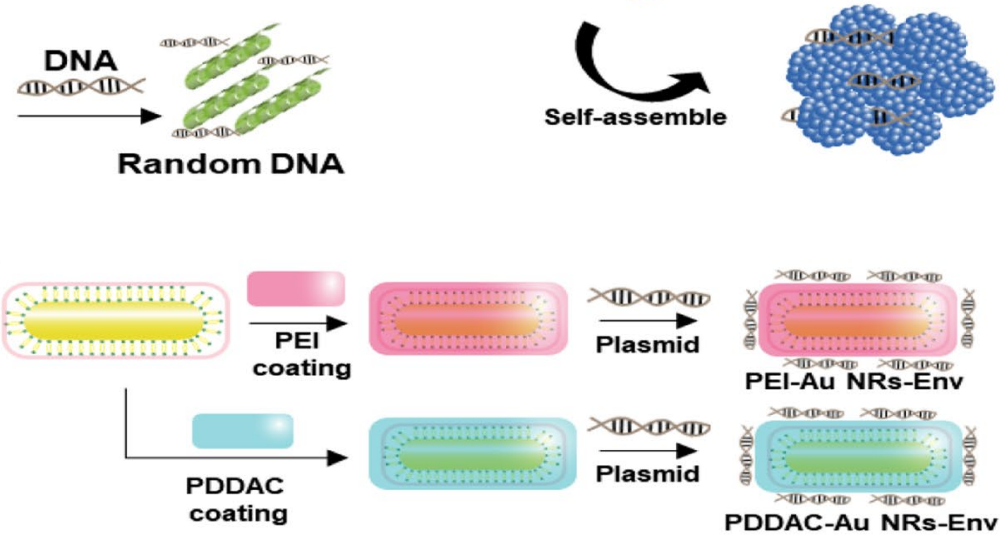

g

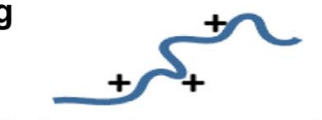

High molar mass pABOLs

$+$

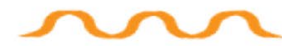

Self-amplifying RNA

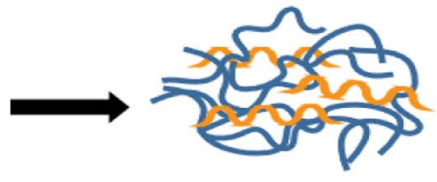

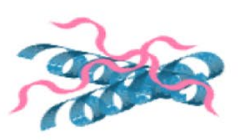

Peptide/mRnA complex
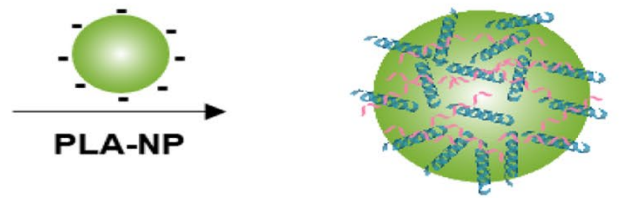

PLA-NP/Peptide/mRNA

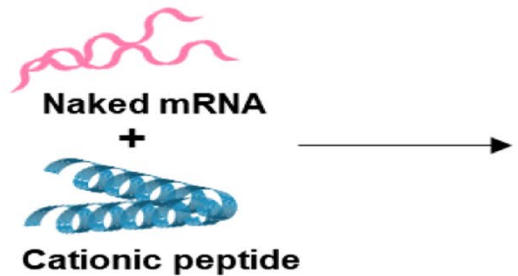

Cationic peptide i

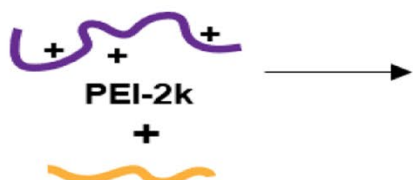

Stearic acid
Fig. 1 Delivery systems of nucleic acids encoding viral antigens. a Mannosylated zwitterionic lipid-based cationic liposomes. Adapted from [15]. b PEI polymeric nanoparticle-coated microneedle. Adapted from [16]. c Peptide nanofiber-based hydrogel. Adapted from [18]. d Fullerenol nanoparticles. Adapted from [19]. e Cationic polymer- modified gold nanorods. Adapted from [17]. f Dendrimer-based nanomaterials for RNA vaccine delivery. Adapted from [27]. g saRNA polyplexes with high molar mass pABOLs. Adapted from [28]. h PLA-based cationic peptides/mRNA nanocomplex. Adapted from [31]. i Co-polymer based cationic nanomicelles. Adapted from [30] 
Mannose-conjugated zwitterionic lipid was used as a component of cationic liposomes. In mice, intramuscular administration of the lipoplexes of mannose-modified cationic liposomes loaded with DNA encoding HIV-1 env was shown to provide higher immune responses compared to those seen in other groups, such as those receiving commercial Lipofectamine 2000-complexed DNA encoding HIV-1 env or a mixture of CpG adjuvant and DNA encoding HIV-1 env. The populations of HIV-specific T cells and the secretion levels of cytokines such as tumor necrosis factor (TNF)- $\alpha$ and interferon (IFN)- $\gamma$ were highest in mice treated with the lipoplexes of mannose-modified cationic liposomes and DNA encoding HIV-1 env. The distribution of administered DNA vaccine to the lymph nodes was greater in the group treated with these lipoplexes compared to the other groups. Although this study showed that mannose modification could increase distribution to the lymph nodes, further studies should examine how mannose modification impacts endosomal escape to the cytoplasm and/or use a challenge model to examine the protection effect of the lipoplexes against HIV infection.

Another study used mannosylated cationic lipid nanoparticles to deliver self-amplifying RNA (saRNA) for influenza virus vaccination [21]. The saRNA was constructed by displacing the RNA sequence of viral structural proteins with that of the desired antigen. Through its self-amplification ability, saRNA is designed to increase the amounts of antigen expressed in the host cells [25]. In the study by Goswami and colleagues, an saRNA vaccine encoding influenza virus hemagglutinin was complexed to mannosylated cholesterolcontaining cationic lipid nanoparticles. As a cationic lipid, 1,2-dilinoleyloxy-3-dimethylaminopropane was used as a component of the nanoparticle. Both intramuscular and intradermal administration of saRNA complexed with mannosylated cationic lipid nanoparticles were shown to provide greater hemagglutinin inhibitor titers, $\mathrm{CD} 4^{+} \mathrm{T}$ cell responses, and $\mathrm{CD}^{+} \mathrm{T}$ cells responses compared with that of the plain nanoparticle.

Cationic lipid nanoparticles were comprehensively studied for intramuscular and intradermal delivery of influenza virus hemagglutinin mRNA in three animal models [20]. Upon intramuscular or intradermal administration, the lipoplexes of cationic lipid nanoparticle with the mRNA induce potent hemagglutinin-specific antibody and $\mathrm{CD} 4^{+} \mathrm{T}$ cell responses in mice, rabbits, and ferrets. Notably, this study showed that the lipoplex of cationic lipid nanoparticles with hemagglutinin mRNA could protect mice from challenge with homologous and heterologous influenza $\mathrm{H} 1 \mathrm{~N} 1$ virus infection. In mice challenged with heterosubtype A/Puerto Rico/8/1934 H1N1 virus, vaccination with the lipoplex was found to provide survival for 14 days, whereas all mice receiving poly $(\mathrm{C}) \mathrm{RNA}$ complexed with the cationic lipid nanoparticles died within this period.
Although most of the existing studies assessed nanocarriers for the delivery of DNA or mRNA encoding viral antigens, one recent study investigated cationic lipid nanoparticles for the delivery of an mRNA encoding a neutralizing anti-HIV-1 antibody called VRCO1 [26]. In this study, the mRNA encoding VRCO1 was used to replace the costly development of a monoclonal neutralizing antibody. The ionizable cationic lipid, 2,2-dilinoleyl-4-dimethylaminoethyl-[1, 3]-dioxolane, was used as a component of the lipid nanoparticles. Mice intravenously injected with $1.4 \mathrm{mg} / \mathrm{kg}$ of mRNA-cationic lipid nanoparticle complex showed a VRCO1 antibody production level of $70 \mu \mathrm{g} / \mathrm{mL}$ in the plasma at 1 day post-dose. Moreover, a single dose $(1.4 \mathrm{mg} / \mathrm{kg})$ of mRNA lipoplexes was found to protect humanized mice from HIV-1 infection.

In summary, lipid-based systems can be applied to deliver wide range of nucleic acid vaccines including DNA plasmid, mRNA and saRNA. The use of target ligand-derivatives of lipids allows the liposomes to be used for specific immune cell-directed delivery systems. However, the candidate ligands for targeting specific immune cells are limited. It is challenging to identify ligand molecules which are exclusive markers of specific immune cells. With the cell biological and immunological progresses on specific markers of immune cells, the targeted delivery systems will be improved.

\section{Polymer-based systems for delivery of nucleic acid viral vaccines}

Among polymers, cationic polymers have been widely used for nucleic acid vaccine delivery. Similar to cationic liposomes, cationic polymers with positively charged groups can make complexes with nucleic acid vaccines based on charge-charge interaction. The resulting polyplexes are expected to increase the entry of nucleic acid vaccines into immune cells and enhance immune responses.

Cationic polymeric nanoparticles have been studied for the intradermal delivery of a DNA vaccine encoding the influenza H1N1 antigen [16]. The DNA encoding H1N1 antigen was complexed to poly lactic-co-glycolic acid/ polyethyleneimine (PLGA/PEI) nanoparticles. Briefly, PLGA nanoparticles were prepared using W/O/W double emulsion-solvent evaporation. The negatively charged PLGA nanoparticles were coated with positively charged PEI to form PLGA/PEI complexes, which were further complexed with the DNA. The polyplexes were coated on polyvinylpyrrolidone microneedles using the layer-by-layer technique. In HEK293 cells, treatment with the polyplex yielded increased transfection of the DNA plasmid compared to that obtained using PEI polyplex. Intradermal vaccination with a patch of polyplex-coated microneedles yielded 2.2fold higher H1N1-specific IgG titer levels compared with 
that obtained in mice that received intradermal injection with a patch of non-coated microneedles.

Dendrimers have also been used as a platform to deliver mRNA against Ebola virus and influenza H1N1 virus [27]. Modified poly(amido amine) dendrimer was complexed to a Venezuelan equine encephalitis virus replicon RNA encoding the HA protein of H1N1 influenza virus or an RNA encoding Ebola virus glycoprotein. Notably, this study demonstrated that antigen proteins could be expressed in vivo after intramuscular administration of an mRNA platform. Upon influenza $\mathrm{H} 1 \mathrm{~N} 1$ virus challenge, $100 \%$ of mice immunized with H1N1 antigen-encoding mRNA in the dendrimer polyplex survived while all the mice treated with ovalbumin fragment-expressing mRNA in the dendrimer complex died after 7 days. Upon Ebola virus challenge, 100\% protection was observed in the mice immunized with Ebola glycoprotein-encoding mRNA in dendrimer complexes, while control mice all died within 10 days.

The high-molecular-weight cationic polymer, poly $\left(\mathrm{N}, \mathrm{N}^{\prime}-\right.$ cystaminebis(acrylamide)-co-4-amino-1-butanol), was used to deliver saRNA encoding hemagglutinin against influenza virus [28]. This study revealed that the molecular weight of the cationic polymer affected the transfection efficiency, with a $100-\mathrm{kDa}$ polymer showing a higher efficiency than 5-92 kDa polymers. After intramuscular injection, the polyplex of saRNA and the 100-kDa cationic polymer showed 4-fold higher serum levels of hemagglutinin-specific $\operatorname{IgG}$ antibodies and neutralization titers compared to those obtained with the polyplex of saRNA with PEI, and provided complete protection from influenza virus challenge.

Another study used chitosan and alginate nanogel to deliver saRNA encoding hemagglutinin or nucleoprotein [29]. This nanogel was composed of chitosan cores formed by chitosan/tripolyphosphate and coated with alginate. The nanogel loaded with saRNA showed greater uptake by dendritic cells compared to naked saRNA. Three subcutaneous immunizations of mice with nanogel loaded with saRNA encoding hemagglutinin or nucleoprotein led to the induction of anti-hemagglutinin or anti-nucleoprotein antibodies. In a rabbit model, three subcutaneous immunizations triggered the development of antigen-specific IgG antibodies.

Cationic polymeric micelles have been studied for the subcutaneous delivery of mRNA encoding HIV-1 gag [30]. A hydrophobic stearic acid derivative of cationic branched PEI (m.w. $2 \mathrm{kDa}$ ) was self-assembled to form micelles that harbored cationic charges on their surfaces. The uptake of mRNA by the DC 2.4 dendritic cell line was enhanced after cationic micelle-based delivery compared to delivery with PEI polyplexes alone. Subcutaneous injection of mice with mRNA encoding HIV-1 gag in the cationic polymeric micelle complexes yielded higher serum levels of antigenspecific $\operatorname{IgG}, \operatorname{IgG} 1$, and $\mathrm{IgG} 2$ a compared with the groups treated with naked mRNA or mRNA in PEI polyplexes. The percentage of HIV gag-specific IFN- $\gamma$-positive cells was higher in the group immunized with mRNA in polymeric micelle complexes compared to those immunized with PEImRNA polyplexes.

Delivery of mRNA encoding HIV-1 gag was also studied using cationic cell-penetrating peptide and polylactide nanoparticles [31]. Polylactide nanoparticles were reported to biodegrade to lactic acid in vivo [32], and to be taken up by dendritic cells in vivo [33]. A cationic cell-penetrating peptide (LAH4-L1) was used to adsorb negatively charged mRNA onto the negative surfaces of polylactide nanoparticles. The triplex of mRNA, cationic cell-penetrating peptide, and polylactide nanoparticles was found to yield increased expression of HIV-gag protein in dendritic cells compared with naked mRNA. In this study, the triplex system was found to increase the production of pro-inflammatory cytokines (IL- $1 \alpha$, IL- 6 , IFN- $\alpha$, and IFN- $\gamma$ ), indicating the activation of Th1-oriented immune responses.

In summary, various polymers such as PEI, poly(amido amine) dendrimer, poly $\left(\mathrm{N}, \mathrm{N}^{\prime}\right.$-cystaminebis(acrylamide)co-4-amino-1-butanol) or chitosan have been studied for nucleic acid vaccine development. Compared with the cationic liposomes, cationic polymers have advantages of less manufacturing processes. Unlike liposomes which need to go through the self-assembly nanoparticle process, extrusion, and complexation processes, polymers need the mixing process with the nucleic acid vaccines. However, polymeric delivery systems confront the biodegradation issues. The list of biocompatible and biodegradable polymers for nucleic acid delivery systems need to be extended in the future.

\section{Other nucleic acid vaccine delivery systems}

Compared to the number studies that have tested lipid or polymer-based nanomaterials, far fewer studies have tested other materials. Several alternative materials have been tested for the delivery of DNA against HIV infection, including peptide nanofibers [18], inorganic gold nanorods [17], and carbon-based nanomaterials [19]. As routes of administration, the intramuscular, intradermal, and subcutaneous routes were studied.

Peptide nanofibers were used to deliver DNA encoding HIV-1 env protein pg 145 [18]. This study exploited the selfassembly of naphthalene acetic acid-GFFY-NMe peptide to nanofiber. The nanofibers of naphthalene acetic acid-GFFYNMe formed a hydrogel in an aqueous solution, and DNA encoding HIV-1 env was loaded to the hydrogel through interaction with the peptide nanofiber. In this study, the intramuscular, intradermal, and subcutaneous administration routes were studied. In all three routes, DNA-entrapped nanofibrous hydrogel yielded increased cellular and humoral immunity compared with naked plasmid DNA and the polyplexes of DNA with PEI. 
Surface-engineered gold nanorods have been reported for the intradermal delivery of a DNA vaccine against HIV infection [17]. For complexation with DNA encoding HIV-1 env, cationic gold nanorods were formulated. As cationic molecules, poly (diallydimethylammonium chloride), PEI, or cetyltrimethylammonium bromide were tested for their ability to confer a cationic feature on the surfaces of the gold nanorods. Compared with the cationic surfactant cetyltrimethylammonium bromide-coated nanorods, poly (diallydimethylammonium chloride)-coated nanorods or PEI-coated nanorods showed lower toxicity to HEK293 cells with higher transfection efficiency. Both poly (diallydimethylammonium chloride)-coated nanorods and PEI-coated nanorods were shown to induce maturation of dendritic cells and enhance cellular and humoral immune responses relative to the groups treated with naked plasmid DNA encoding HIV-1 env or with cetyltrimethylammonium bromide-coated nanorods as a carrier.

A carbon-based fullerenol nanoparticle was investigated for intradermal delivery of DNA encoding HIV-1 env [19]. Fullerenol is a polyhydroxylated fullerene C60 derivative that can form nano-aggregates in aqueous solution. In this study, fullerenol nanoparticles were used to mimic the virus-like three-dimensional morphology for DNA vaccine delivery system. DNA encoding HIV-1 env was complexed to fullerenol nanoparticle by hydrogen bonding, and intradermally administered to mice. A greater HIV-1 env-specific antibody IgG titer was observed in the group treated with DNA in fullerenol nanoparticle complexes compared to the naked DNA treatment group. Moreover, vaccination with fullerenol-DNA antigen complexes $(0.5 \mathrm{mg} / \mathrm{kg}$ DNA) induced stronger cellular immune responses compared to naked DNA vaccination $(0.5 \mathrm{mg} / \mathrm{kg})$ when both were applied as three injections given at 2-week intervals.

When developing delivery systems for nucleic acid vaccine antigens, researchers should validate the intracellular and in vivo antigen expression levels and characterize the physicochemical features, including the loading efficiencies and size of the antigen-encoding nucleic acids in complex with the delivery system. In terms of safety concerns, researchers should study the time-dependent pharmacokinetics and distribution of antigen-encoding nucleic acids to various organs of the body.

\section{Delivery systems for protein vaccines against viral infectious diseases}

Compared with traditional live-attenuated vaccine approaches, protein vaccines offer a major benefit in their improved safety. Because they involve highly purified recombinant antigen proteins, such vaccines can provide safer vaccination due to lack of impurities. Moreover, the use of a protein subunit vaccine can avoid the concerns surrounding the use of a live-attenuated vaccine, which can show complicated reversion to a pathogenic virus in immunocompromised patients [34]. However, soluble protein antigens are easily degraded in vivo and exhibit limited cellular entry with subsequent low immunogenicity [35]. Thus, various nanoparticle delivery systems have been investigated as protein antigen vaccine platforms to support efficient antigen uptake and promote antigen presentation. Examples of protein vaccines are illustrated in Fig. 2.

\section{Polymeric systems for delivery of protein viral vaccines}

To facilitate the entry of protein vaccines into immune cells, various polymers have been investigated. Polymers have been chemically conjugated or modified with functional groups to carry protein antigens. Functional modifications have been approached to provide $\mathrm{pH}$-responsiveness for lysosomal escape, or noncovalent specific loading of protein antigens.

Virus-mimetic polymeric nanoparticles have been studied for influenza A virus nucleoprotein delivery [36]. To mimic the ability of the virus to escape endosomes, researchers introduced to the polymeric nanoparticle a $\mathrm{pH}$-responsive moiety that can increase the endosomal escape of an antigen to the cytoplasm. To provide $\mathrm{pH}$ responsiveness, a two-block copolymer was designed: one block was hydrophilic dimethylaminoethyl methacrylate and pyridyl disulfide ethyl methacrylate; the other block, which was the $\mathrm{pH}$-sensitive part, was composed of propylacrylic acid, butylmethacrylate, and dimethylaminoethyl methacrylate. Influenza A H1N1 nucleoprotein was conjugated to the $\mathrm{pH}$-responsive nanoparticles via thiol-disulfide exchange. To enhance the immunogenicity of the protein antigen, the adjuvant CpG ODN 1826 was encapsulated in the nanoparticles by charge-charge interaction. Immunization of mice with the protein antigen in $\mathrm{CpG}$ ODN-loaded polymeric nanoparticles yielded greater populations of protective $\mathrm{CD} 8^{+}$lung-resident memory $\mathrm{T}$ cells and provided protection against influenza virus challenge. Whereas all control mice died after influenza virus challenge, mice treated with protein antigen in $\mathrm{CpG}$ ODN-loaded polymeric nanoparticles showed $83 \%$ survival.

Polylactide microparticles modified with didodecyldimethylammonium bromide were used for intramuscular delivery of hepatitis B surface antigen [37]. Hepatitis surface antigens were adsorbed onto the surfaces of polylactide microparticles. Three intramuscular injections of antigenloaded polylactide microparticles yielded increased levels of pro-inflammatory cytokines (IL-1 $\beta$, IL-6, CCL2, and CXCL1) at the injection site compared with that seen in mice that received the polylactide microparticle alone. Notably, after the third immunization, the group treated with antigen protein on polymeric nanoparticles exhibited tenfold higher antigen-specific $\operatorname{IgG}$ titers compared to the group treated with commercial alum-adjuvanted antigen. 
Fig. 2 Delivery systems of protein- and VLP-based vaccines against viral infectious diseases. a The 3M2e-rHF fusion protein and $3 \mathrm{M} 2 \mathrm{e}-\mathrm{rHF}$ fusion protein-based nanoparticle. Reprinted with permission from [38]. b Double-layered protein nanoparticles for protein antigen delivery. Reprinted with permission from [39]. c Schematic illustration of the expression and in vivo assembly of P22-SpyTag and preparation of P22-HA head $_{\text {. }}$ Reprinted with permission from [45]. d Schematic illustration of preparation of an avian coronavirus VLP. Reprinted with permission from [50] a

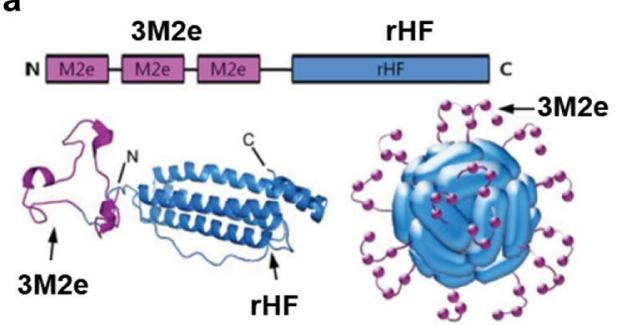

b

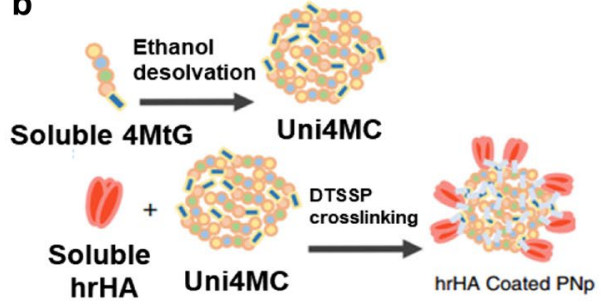

Scaffold protein

C
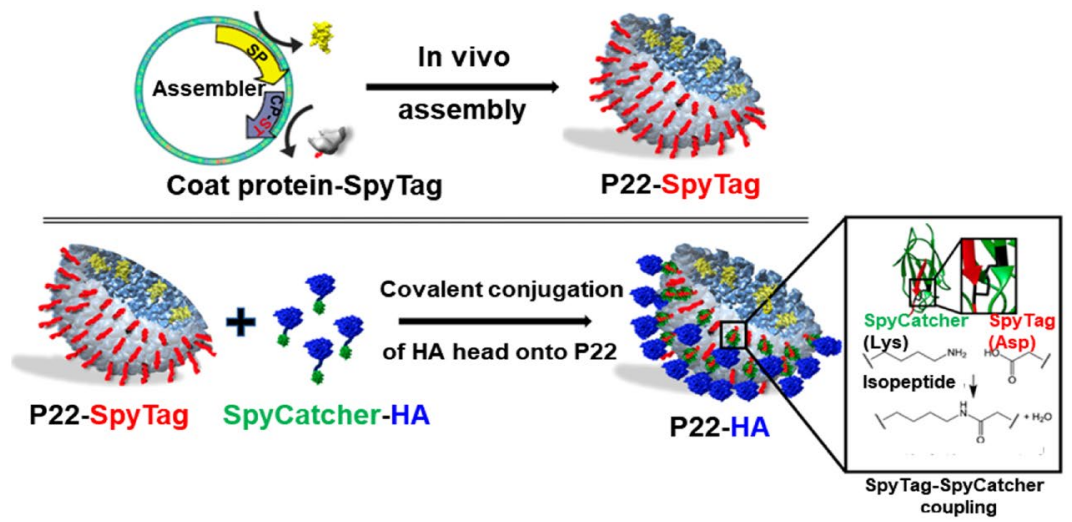

d

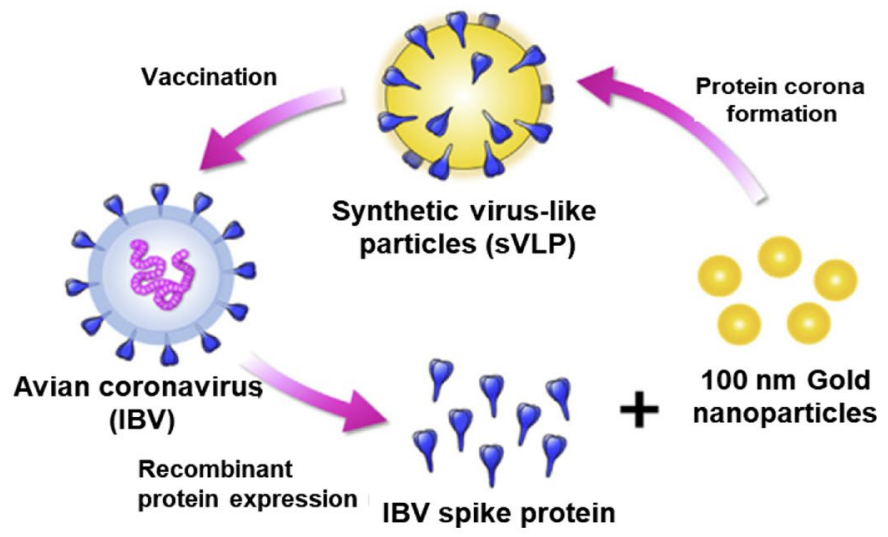

Taken together, several polymer-based delivery systems have been reported to provide immune response against infectious diseases. Although polymers have shown feasibility of protein vaccine delivery, this field is still in infancy. In the cases of polymeric delivery systems, the biological and immunological studies on degradation products need to be done. In addition, the codelivery strategies of immune adjuvants using polymeric systems would be concerns for higher immune responses.

\section{Protein-based nanomaterials for the delivery of protein viral vaccines}

Only a few studies have tested protein-based nanomaterials for vaccine delivery. As protein-based nanomaterials, ferritin [38], self-assembled protein nanoparticle [39], and virus-like particles (VLPs) have been exploited. Ferritin was studied for drug delivery due to its high drug-loading capacity, biocompatibility, and safety [40]. Ferritin was investigated for its ability to deliver doxorubicin to cancer cells via interaction with transferrin receptor 1 , which is overexpressed on cancer cells [41]. Another study used ferritin to deliver cytochrome $\mathrm{c}$ for the induction of apoptosis in myeloid leukemia cells [42]. VLPs are morphologically similar to natural viruses, but lack the viral genetic materials inside. VLPs are composed only of capsid proteins, and thus do not cause infection or proliferate in host cells [43]. VLPs can be naturally obtained or synthesized and self-assembled into viral mimetic structures [44]. Vaccination with VLPs alone has been used clinically for hepatitis B and human papillomavirus vaccination.

In a study using ferritin nanocage for vaccine delivery, three sequential repeats of matrix 2 protein were conjugated to human heavy chain ferritin nanocages [38]. Intranasal 
administration of the viral matrix 2 protein-conjugated ferritin nanocages was found to induce antigen-specific IgG, $\mathrm{IgG} 1$, and $\mathrm{IgG} 2 \mathrm{a}$ in serum, whereas intranasal administration of ferritin nanocage alone did not induce antigen-specific antibodies. No mouse that received intranasal ferritin nanocage was able to survive challenge with influenza virus. In contrast, intranasal immunization of mice with matrix 2 protein-conjugated ferritin nanoparticles provided complete protection against challenge with homologous and heterosubtypic influenza virus, with challenged mice showing $100 \%$ survival.

Another group studied the intramuscular delivery of matrix 2 protein and head-removed hemagglutinin of influenza virus using double-layered protein nanoparticles [39]. Recombinant proteins containing four tandem copies of matrix 2 protein were constructed and self-assembled into protein nanoparticles by the ethanol desolvation method. Head-removed hemagglutinin proteins were then tagged to the surfaces of the matrix 2 protein nanoparticles through 3,3'-dithiobis (sulfosuccinimidyl propionate) crosslinking. Intramuscular administration of matrix 2 protein-loaded protein nanoparticles was found to elicit antigen-specific $\operatorname{IgG}$ antibodies in serum and protected the mice from challenge with mouse-adapted influenza A virus, compared with the phosphate buffer-treated group.

Non-pathogenic VLPs derived from bacteriophage P22 were examined for the intratracheal delivery of influenza virus hemagglutinin [45]. In this study, recombinant hemagglutinin head antigen from PR8 influenza virus was covalently conjugated to the surface of preassembled bacteriophage P22 VLPs through peptide-peptide specific interaction. Hemagglutinin head antigen-conjugated P22 VLPs showed a three-dimensional virus-mimetic morphology. Intratracheal instillation of mice with hemagglutinin head antigen alone yielded $60 \%$ survival and $13 \%$ body weight loss upon challenge with homologous influenza virus. Intratracheal administration of hemagglutinin head antigenconjugated VLPs provided complete protection against the challenge with homologous PR8 influenza virus, with no loss in body weight.

Lass mammarenavirus-like protein nanoparticles were studied for the intramuscular delivery of the glycoprotein of Lassa mammarenavirus [46]. Lassa mammarenavirus is a rodent arenavirus that can cause acute hemorrhagic fever disease in humans [47]. In this study, the glycoprotein was not physically loaded or chemically conjugated; rather it was genetically fused to the gene of Lass mammarenavirus-like protein. Mammalian normal kidney MDCK II cells were used for expression of the genetically fused VLPs. The presence of glycoprotein on the surfaces of genetically engineered VLPs was aimed to mimic the natural Lassa mammarenavirus, which has glycoproteins on its surface. The administration of glycoprotein-fused VLPs was shown to elicit neutralizing antibody responses in the serum of rabbits. As an adjuvant, the toll-like receptor 4 agonist, monophosphoryl lipid A, was dispersed in an oil (squalene)/water emulsion. The combination of glycoprotein-fused VLPs with the squalene-based adjuvant increased the induction of neutralizing antibodies against five genetic lineages of Lassa mammarenavirus.

Influenza H1N1 VLPs were expressed from plant cells and studied as a potential vaccine against influenza virus [48]. The plant-derived VLPs were generated from Nicotiana benthamiana that had been pre-engineered to express influenza hemagglutinin. Hemagglutinin-bearing VLPs showed pleomorphic particulate structures similar to that of the native influenza virus and underwent 3-fold higher endocytosis by human monocyte-derived macrophages compared to hemagglutinin protein alone. Notably, this study observed the intracellular fate of the genetically fused VLPs. In human monocyte-derived macrophages, fluorescent dye-tagged genetically fused VLPs showed entry into early, late, and recycling endosomal pathways. At $45 \mathrm{~min}$ after pulse, the fluorescent dye-tagged genetically fused VLPs were found to be co-localized with MHC II, MHC I, and endosomal markers (Rab5, Rab7, and Rab11).

Compared with the many studies that have examined the use of lipid or polymeric nanoparticles for vaccine delivery, the studies using protein-based nanomaterials are limited. One reason for this is the complexity of constructing and producing protein-based nanomaterials. Another is the possibility for a protein-based nanomaterial to function as an antigen and trigger immune responses. Thus, the study of protein-based delivery systems should include evaluation of antibody development after repeated dosing.

\section{Inorganic nanomaterials for the delivery of protein viral vaccines}

Among the inorganic nanomaterials, metallic silver and gold nanoparticles have been studied for delivering influenza virus [49] and avian coronavirus [50]. Silver nanoparticles themselves have been reported to modulate innate immune responses and promote the pro-inflammatory cytokine release in innate immune cells [51]. Silver nanoparticles are known to have high surface energies, driving protein adsorption on the surface [52]. Gold nanoparticles are also known to have a high surface energy for protein adsorption [53].

Silver nanoparticles were applied for intratracheal delivery of heat-inactivated influenza A virus vaccine [49]. Using the protein adsorption feature of silver nanoparticles, the heat-inactivated influenza A virus was physically adsorbed on the surfaces of silver nanoparticles. After intratracheal injection, mice immunized with the virus adsorbed on silver nanoparticles showed enhanced levels of IL-12 and B-cell 
activating factor in bronchoalveolar lavages. Immunization with the virus antigen on silver nanoparticles protected mice from challenge with sub-lethal doses (300 pfu/mouse) of the same strain of influenza A virus. Mice immunized with the virus adsorbed on silver nanoparticles provided higher levels of antigen-specific IgA in bronchoalveolar lavages and antigen-specific IgG in serum, compared to the group immunized with head-inactivated virus alone.

Gold nanoparticles were studied for delivery of the capsid proteins of avian coronavirus [50]. In this study, capsid proteins were physically adsorbed on the surfaces of gold nanoparticles, where they formed three-dimensional virus-like structures. Intramuscular delivery of the capsid proteins adsorbed on the gold nanoparticles showed 6-fold higher distribution to draining lymph nodes compared to that achieved using free capsid proteins. In a chicken model, intramuscular injection of the capsid proteins adsorbed on the gold nanoparticles provided higher anti-infectious bronchitis virus spike protein IgG and IgA antibody titers and splenic $\mathrm{T}$ cells responses than administration of free capsid proteins, and provided complete protection against challenge with infectious bronchitis virus.

Metallic silver or gold nanoparticles may have advantages in protein vaccine formulations due to their proteinadsorption features. However, the safety of any metallic nanomaterial should be carefully considered. Due to their lack of biodegradation in the body, metallic nanoparticles may be retained in the body for prolonged periods, and thus may exert unexpected side effects. It has been reported that nanoparticles smaller than $10 \mathrm{~nm}$ can be excreted via the kidney [54]. Fabrication of metallic nanoparticles in excretable sizes would be one way to minimize the safety concerns. In the future, it could be useful to study the impact of metallic nanoparticle size on immune responses.

\section{Nanovaccines against recently emerging infectious viral diseases}

Despite advances in public health and ongoing development of therapeutics, pandemic infectious diseases still threaten humanity. In particular, as can be seen from the current epidemic of COVID-19, preventing the sudden spread of infectious diseases and intervention through the development of appropriate vaccines will be essential for human health moving forward [55]. In this context, the World Health Organization has selected nine priority diseases that are projected to cause the greatest public health risk and has announced that research and development should be intensively followed in order to be prepared for future outbreaks. The nine priority diseases are COVID-19, Crimean-Congo hemorrhagic fever, Ebola virus disease, Marburg virus disease, Lassa fever, MERS, severe acute respiratory syndrome (SARS),
Nipah and henipaviral diseases, Rift Valley fever, Zika, and Disease X. Given the unmet clinical and social needs for the fast development of vaccines against these priority diseases, this section separately addresses the nanovaccines currently being studied against recently emerging infectious viral diseases, along with their clinical significances. The types of various nanotechnology-based vaccines against recently emerging infectious viral diseases are listed in Table 2.

\section{Nanovaccines against SARS-CoV-2}

COVID-19 is unprecedented pandemic infection, affecting society and economy worldwide. It is caused by SARSCoV-2, which was first identified in December 2019 [56]. With fever and cough as its main symptoms, SARS-CoV-2 is strongly contagious and has spread around the world. The World Health Organization declared a global pandemic on 11 March 2020. As of October 3, 2020, there have been $34,396,222$ confirmed cases and the number of infected people keeps increasing. Given the lack of a preventive strategy other than social distancing and wearing masks, the need for vaccine development is increasingly urgent.

SARS-CoV-2 belongs to the betacoronavirus family, whose members have a viral envelope and a single-stranded RNA genome [57]. The corona structure of this virus is formed by spike-like glycoproteins on the outer membrane. There are four major structures that may be suitable target candidates for vaccine development: the spike (S) glycoprotein, the membrane $(\mathrm{M})$ protein, the envelope $(\mathrm{E})$ protein, and the nucleocapsid $(\mathrm{N})$ protein [58]. Although only limited information is available about SARS-CoV-2 due to the suddenness of the outbreak, its structure resembles those of better-known coronaviruses [59]. By referring to accumulated databases harboring information on the previous coronavirus-caused infections (e.g., those of SARS and MERS) and using bioinformatics to predict the epitope structure, researchers worldwide have made rapid progress, and a few vaccines have already been approved in some countries [60].

Clinical trial phase I is ongoing using ionizable lipidbased nanoparticles for delivery of mRNA encoding the receptor binding domain of SARS-CoV-2 [61]. In this report, the lipid nanoparticles were composed of ionizable lipid 1,2-distearoyl-sn-glycero-3-phosphocholine, cholesterol, and pegylated lipids at a molar ratio of 50:10:38.5:1.5. The lipids in ethanol were mixed with citrate buffer $(\mathrm{pH} 4.0)$ containing mRNA through a T-shaped microfluidic mixer, and particles were formed through nanoprecipitation. The intramuscular administration of nanoparticles entrapping the mRNA of SARS-CoV-2 was shown to yield antigen protein expression at the injection site and induce significant SARS$\mathrm{CoV}-2$-specific IgG and neutralizing antibodies against three different epidemic strains of SARS-CoV-2, whereas no antibody elevation was detected in mice injected with empty 
Table 2 The types of various nanotechnology-based vaccines against recently emerging infectious viral diseases

\begin{tabular}{|c|c|c|c|c|c|c|}
\hline Target virus & Vaccine type & Antigens & Formulation & Route & Animal model & Reference \\
\hline \multirow[t]{3}{*}{ SARS-CoV-2 } & \multirow[t]{3}{*}{ Nucleic acid } & $\begin{array}{l}\text { mRNA encoding the } \\
\text { SARS-CoV-2 RBD }\end{array}$ & Lipid nanoparticle & Intramuscular & $\begin{array}{l}\text { Balb/c mice, cynomolgus } \\
\text { monkeys }\end{array}$ & 61 \\
\hline & & $\begin{array}{l}\text { Self-amplifying RNA } \\
\text { encoding the SARS- } \\
\text { CoV-2 spike protein }\end{array}$ & Lipid nanoparticle & Intramuscular & Balb/c mice & 62 \\
\hline & & $\begin{array}{l}\text { Self-amplifying RNA } \\
\text { encoding the SARS- } \\
\text { CoV-2 spike protein }\end{array}$ & Emulsion & Intramuscular & $\mathrm{Balb} / \mathrm{c}$ mice & 63 \\
\hline \multirow[t]{2}{*}{ MERS-CoV } & \multirow[t]{2}{*}{ Protein } & MERS-CoV RBD & Polymeric nanoparticle & Subcutaneous & C57BL/6 mice & 67 \\
\hline & & MERS-CoV RBD & Protein-based nanoparticle & Intramuscular & Balb/c mice & 68 \\
\hline \multirow[t]{4}{*}{ ZIKA virus } & \multirow[t]{4}{*}{ Nucleic acid } & $\begin{array}{l}\text { mRNA encoding pre- } \\
\text { membrane and envelope } \\
\text { glycoproteins }\end{array}$ & Lipid nanoparticle & Intradermal & $\begin{array}{l}\text { Balb/c mice, } \\
\text { rhesus macaques }\end{array}$ & 74 \\
\hline & & $\begin{array}{l}\text { mRNA encoding pre- } \\
\text { membrane and envelope } \\
\text { glycoproteins }\end{array}$ & Lipid nanoparticle & Intramuscular & $\mathrm{Balb} / \mathrm{c}$ mice & 75 \\
\hline & & $\begin{array}{l}\text { mRNA encoding pre- } \\
\text { membrane and envelope } \\
\text { glycoproteins }\end{array}$ & $\begin{array}{l}\text { Dendrimer-based nano- } \\
\text { particle }\end{array}$ & Intramuscular & C57BL/6 mice & 76 \\
\hline & & $\begin{array}{l}\text { DNA encoding pre- } \\
\text { membrane and envelope } \\
\text { glycoproteins }\end{array}$ & Polymeric nanoparticle & Intramuscular & C57BL/6 mice & 77 \\
\hline \multirow[t]{3}{*}{ Ebola virus } & \multirow[t]{2}{*}{ Protein } & Ebola virus spike protein & Lipid nanoparticle & Subcutaneous & C57BL/6 mice & 81 \\
\hline & & Ebola virus spike protein & Lipid nanoparticle & Subcutaneous & C57BL/6 mice & 82 \\
\hline & Nucleic acid & $\begin{array}{l}\text { DNA encoding Ebola } \\
\text { virus glycoprotein }\end{array}$ & Polymeric nanoparticle & $\begin{array}{l}\text { Microneedle } \\
\text { patch }\end{array}$ & $\begin{array}{l}\text { Mice from Charles River } \\
\text { Laboratory }\end{array}$ & 83 \\
\hline
\end{tabular}

lipid nanoparticles. The immunization also induced SARSCoV-2 specific CD4+ and CD8+ effector memory T cells in spleen. The lipid nanoparticle with the mRNA was observed to be stable at room temperature for up to 7 days in storage.

Lipoplexes of saRNA with cationic lipid nanoparticles were reported as a feasible nanovaccine against SARS-CoV-2 [62]. The cationic lipid nanoparticles were composed of an ionizable cationic lipid (proprietary to Acuitas), phosphatidylcholine, cholesterol, and pegylated lipid at a molar ratio of 55:10:32.5:2.5. They were complexed to saRNA encoding SARS-CoV-2 spike protein through a self-assembly process in which the lipid solution in ethanol was rapidly mixed with the mRNA in aqueous solution at pH 4.0. In a mouse model, the repeated intramuscular administration of lipoplexes of saRNA at 1-month intervals was shown to elicit SARSCoV-2 specific IgG antibodies and neutralize infection with wild-type SARS-CoV-2 in a dose-dependent manner. Restimulation of splenocytes of the immunized mice with SARS$\mathrm{CoV}-2$ antigen provided a significant increase of IFN- $\gamma$. In the sera of the lipoplex-immunized mice, the authors observed elevated levels of cytokines and chemokines, including IL-6, macrophage inflammatory protein-1 $\beta$, RANTES (regulated on activation, normal $\mathrm{T}$ cell expressed and secreted), IFN- $\beta$, and interferon- $\gamma$-inducible protein- 10 .
In a nonhuman primate animal model, an inorganic nanoparticle-containing cationic squalene emulsion was investigated for intramuscular delivery of saRNA for the SARS-CoV-2 spike protein [63] (Fig. 3). The cationic emulsion was composed of cationic lipid 1,2-dioleoyl-3trimethylammonium propane (DOTAP), Span 60, Tween 80 , and squalene. In the squalene-based oil phase, 15-nmsized superparamagnetic iron oxide nanoparticles were loaded to enhance the stability of the emulsion. The cationic emulsion was complexed to an anionic saRNA vaccine encoding SARS-CoV-2 spike protein by chargecharge interaction. The emulsion complex form could protect saRNA from RNase degradation, and maintained its short-term stability up to 7 days. In mice, intramuscular administration of saRNA complexed to the cationic emulsion was found to elicit anti-SARS-CoV-2 spike proteinspecific IgG antibodies in the serum and increase IFN- $\gamma$ levels in the spleen and lung. Notably, the immunization of pigtail macaques (a nonhuman primate) with the saRNA vaccine complexed to the cationic emulsion was shown to induce anti-SARS-CoV-2 spike protein-specific IgG antibody responses persisting up to 70 days. The relationship between the doses and the duration of persistence may warrant further attention in the near future. 
Fig. 3 Illustration of a nanovaccine against COVID-19. a Cationic squalene emulsion was composed of cationic lipid DOTAP, Span60, Tween 80, and squalene. To enhance the stability of the formulation, superparamagnetic iron oxide nanoparticles (SPIO) were loaded in oil phase. The formulation was complexed with saRNA (repRNA-CoV25) for intramuscular delivery. Adapted from [63]. b After endocytosis, SAS-CoV2-encoding saRNA was translated to the spike protein, and processed in antigen presenting cells. MHC I and MHC II antigen presentations induced SARS-CoV-2 specific cellular and humoral immune responses, respectively
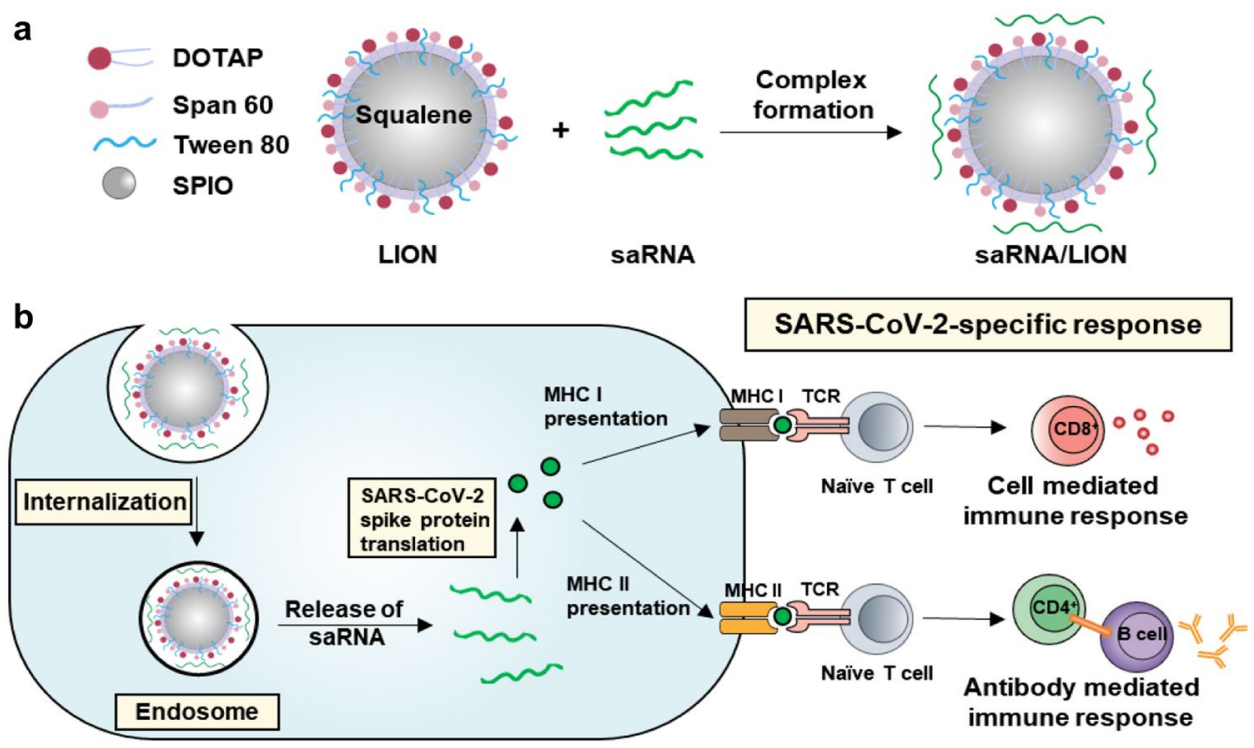

Antigen presenting cell
RNA-based vaccines now have made a great achievement with approvals for human use. The development of lipid formulation techniques facilitated the delivery of RNAbased vaccines to the immune cells, and enabled the immune responses. RNA-based vaccines have great advantages of coping with variants of viral pathogens, since they do not need time-consuming protein design, expression, and purification processes. In line with the delivery system developments, the modification techniques of stabilizing antigenencoding RNA attributed to the clinical success.

\section{Nanovaccines against MERS-CoV}

MERS-CoV, which was first identified in Saudi Arabia in 2012, is a viral respiratory disease caused by coronavirus [64]. More than 2000 cases MERS-CoV infection, which has typical symptoms including fever, cough, and shortness of breath, have been reported by WHO since September 2012 in around 27 countries [65]. MERS-CoV is a zoonotic virus that arose in dromedary camel; it is transmitted by close contact between humans, and has a high case-fatality rate of $37.1 \%$ [66]. MERS-CoV infection is listed as a priority disease in need of urgent R\&D attention by WHO, and vaccines are needed in the near future to prevent severe outbreaks of MERS-CoV.

PLGA nanoparticles have been studied for the delivery of recombinant MERS-CoV receptor binding domain antigens [67]. As an adjuvant, the stimulator of interferon genes (STING) agonist, c-di-GMP, was encapsulated in the nanoparticles. Recombinant MERS-CoV receptor binding domain antigens were covalently conjugated to adjuvantencapsulated polymeric nanoparticles containing a maleimide derivative of pegylated lipids. Subcutaneous injection with the antigen-conjugated and adjuvant-entrapped polymeric nanoparticles yielded higher titers of antigen-specific antibodies than seen in the group treated with a physical mixture of c-di-GMP and the recombinant antigen proteins. In human dipeptidyl peptidase 4 transgenic mice, which are susceptible to MERS-CoV infection, $100 \%$ of mice immunized with the antigen-conjugated and adjuvant-entrapped polymeric nanoparticles were protected from infection with MERS-CoV, while all mice treated with only adjuvant-entrapped polymeric nanoparticles died by day 16 post-infection.

In another study, genetic fusion protein-based nanoparticles were studied as a potential MERS-CoV vaccine [68] (Fig. 4). In the fusion protein, the receptor binding domain of MERS-CoV virus was genetically engineered to co-express an RNA-binding domain and ferritin. The RNA-binding domain was introduced to interact with an RNA chaperone, such that the protein would be properly folded after being translated in bacteria. Ferritin was introduced as a self-assembly scaffold for the nanoparticles. As an additional linker peptide, an SSG or ASG linker was introduced between the receptor-binding domain and ferritin. Among the protein nanoparticles formed from fusion proteins with different linker peptides, nanoparticles with the SSG linker yielded the highest antigen-specific IgG and IgA titers. The intramuscular administration of the protein nanoparticle with the SSG fusion linker also induced a cellular immune response in mice, which was reflected by increased production of IFN- $\gamma$ and TNF- $\alpha$ from splenocytes.

\section{Nanovaccines against ZIKA virus}

Zika virus is a flavivirus of the Flaviviridae family, whose members have a positive-sense single-stranded RNA genome with structural capsid proteins and an 
< Fusion partner $><$ Target protein $><$ Nanoparticle $>$
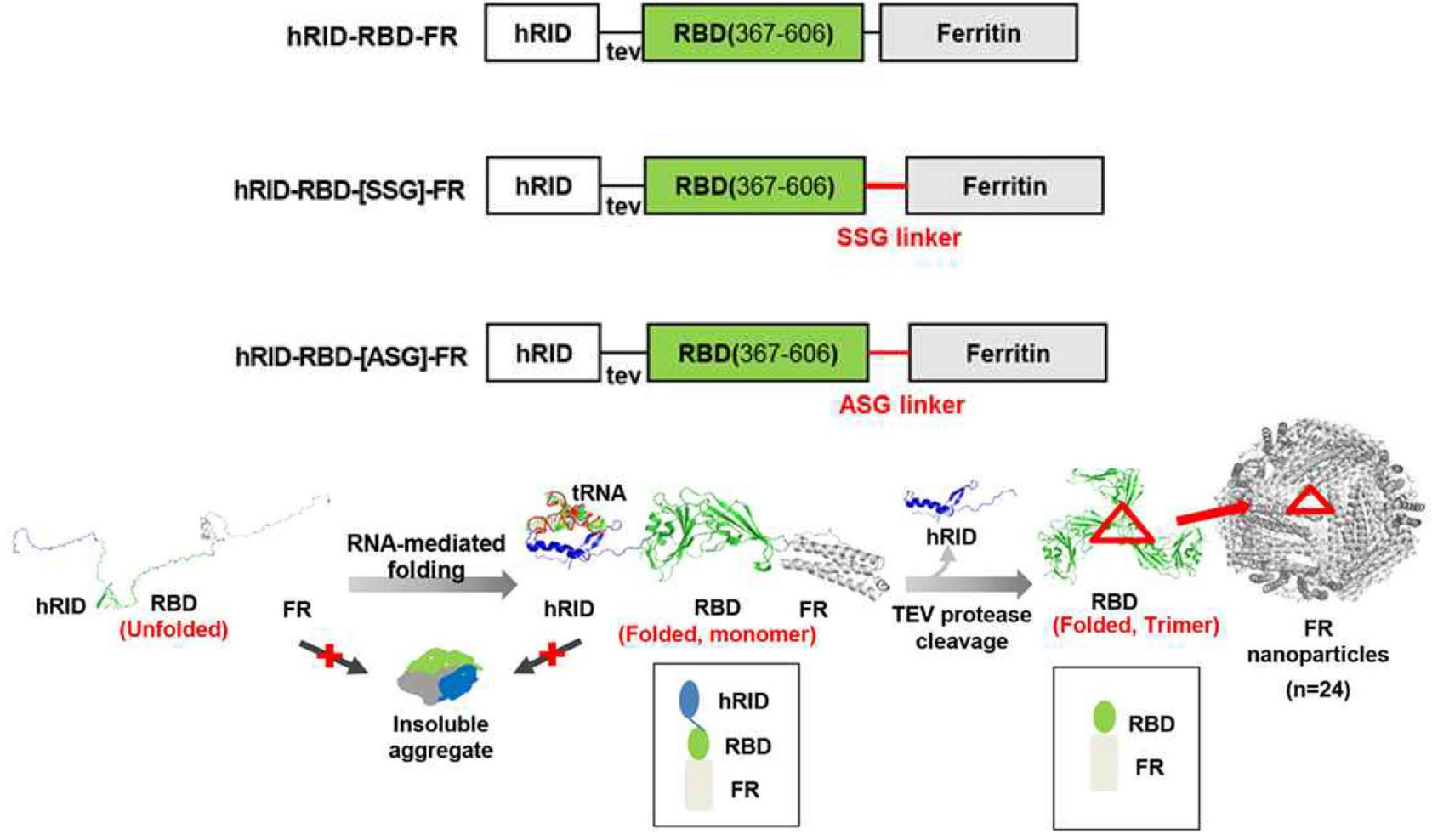

Fig. 4 Ferritin-fused protein nanoparticles against MERS-CoV. Fusion proteins were composed of RNA binding domain (hRID), the receptor-binding domain (RBD) of MERS-CoV, and ferritin. Three fusion proteins were designed with different linker peptides between ferritin and RBD. Reprinted with permission from [68]

the lipids in ethanol were rapidly mixed with the mRNA in aqueous solution at $\mathrm{pH} 4$ during the nanoparticle assembly process. As mRNA, nucleoside-modified mRNA encoding the pre-membrane and envelope glycoproteins of Zika virus (ZIKV H/PF/2013) was used. Intradermal administration of the modified mRNA in lipoplexes increased the production of IFN- $\gamma$, TNF, and IL- 2 by splenocytes and protected nonhuman primate rhesus macaques against Zika virus challenge at 5 month post-immunization.

Cationic lipid nanoparticles were studied for the intramuscular delivery of an mRNA vaccine against Zika virus [75]. The nanoparticles were composed of 3-(dimethylamino)propyl(12Z,15Z)-3-[(9Z,12Z)-octadeca-9,12-dien-1yl]henicosa-12,15-dienoate, 1,2-distearoyl-sn-glycero-3phosphocholine, cholesterol, and pegylated lipids at a molar ratio of 50:10:38.5:1.5. As a vaccine antigen, the researchers developed a modified mRNA lacking the conserved fusionloop epitope in the envelope protein. In mice, intramuscular administration of the modified mRNA in lipoplexes elicited neutralizing antibodies in the serum and provided $100 \%$ survival after challenge with Zika virus. The levels of neutralizing antibodies were found to persist until 14 weeks post-immunization. 
Dendrimer nanoparticles were used for the intramuscular delivery of an mRNA encoding the envelope protein of Zika virus [76]. The dendrimer nanoparticles were composed of a modified ionizable dendrimer based on poly(amido amine) dendrimer, with an ethylenediamine core and pegylated lipids. The complexes of the mRNA and dendrimer nanoparticles elevated the levels of Zika virus envelope proteinspecific IgG antibodies in serum. The stimulation of splenocytes with IGVSNRDFV, an immunodominant MHC class I-restricted epitope of the envelope protein, was found to increase the populations of $\mathrm{CD} 8+\mathrm{T}$ cells producing IFN $-\gamma$.

Block copolymer-based polymeric nanoparticles were studied for the delivery of a DNA vaccine against Zika virus [77]. In this study, a tetrafunctional amphiphilic block copolymer composed of poly(ethylene oxide)/poly(propylene oxide) blocks with an ethylenediamine center moiety was used to load DNA encoding the full sequences of the pre-membrane and envelope glycoproteins. Through hydrogen bonding, hydrophobic interactions, and charge interactions, the amphiphilic block copolymer and antigen-encoding DNA could form stable complexes. Intramuscular injection of mice with the DNA-loaded polyplexes induced neutralizing antibodies and protected the mice from Zika virus challenge for more than 7 months post-immunization.

\section{Nanovaccines against Ebola}

Ebola virus infection, which is also referred to as Ebola hemorrhagic fever, is a lethal disease characterized by high fever, headache, muscular pain, and hemorrhage [78]. The most commonly known Ebola virus is Zaire Ebola virus, which has a negative-sense, single-stranded RNA with helical nucleocapsids, and is transmitted by direct contact with body fluid or contaminated fomites [79]. Since the first outbreak of Ebola in the Democratic Republic of Congo in 1976, Ebola virus infection has recorded a steady death rate per year [80]. The biggest outbreak of Ebola to date occurred in West Africa in 2014; it caused more than 28,600 infections and 11,325 deaths.

A lipid and biopolymer hybrid nanoparticle was investigated for the subcutaneous delivery of the Ebola virus spike glycoprotein [81]. The hybrid nanoparticles consisted of various lipids, including 1,2-dioleoyloxy-3-(trimethylammonium) propane, 1,2-dioleoyl-sn-glycero-3-phosphocholine, and maleimide-functionalized N-(4-carboxybenzyl)-N,N-dimethyl2,3-bis(oleoyloxy)propan-1-aminium, which were crosslinked with thiolated hyaluronic acid. As an adjuvant, the toll-like receptor 4 agonist, monophosphoryl lipid A, was loaded in the hydrophobic lipid parts of the hybrid nanoparticles. Ebola

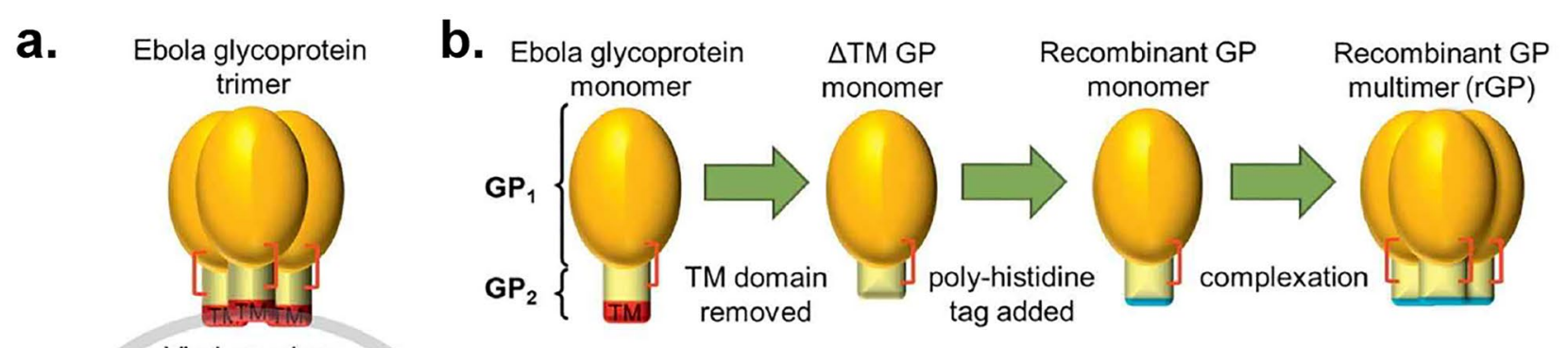

Viral envelope

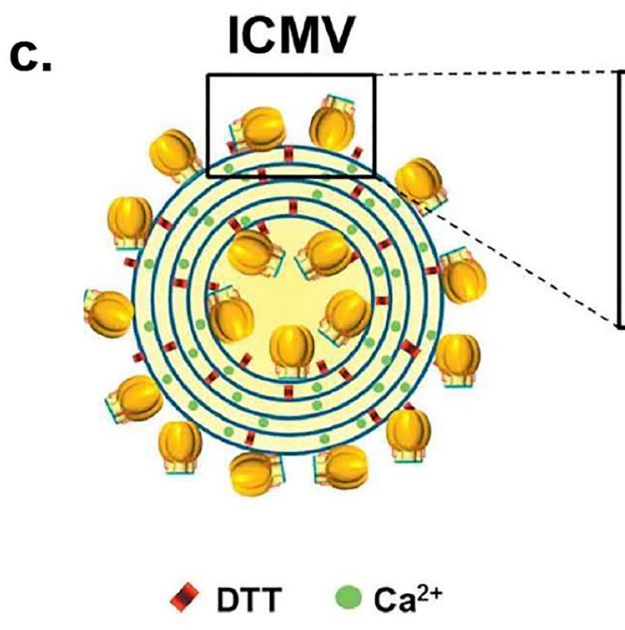

Nanoparticle surface

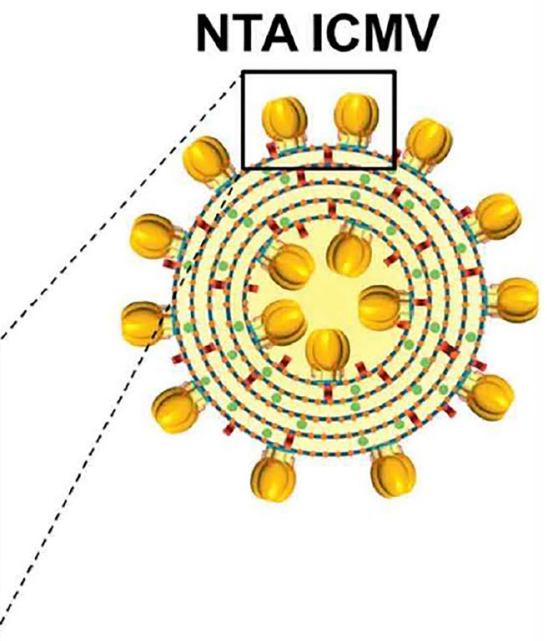

Fig. 5 Lipid nanoparticles for delivery of Ebola virus glycoprotein. Ebola virus glycoproteins were loaded to lipid nanoparticles via hisNTA nitrilotriacetic acid, ICMV interbilayer-crosslinked multilameltidine and nickel interactions. Reprinted with permission from [82]. 
virus spike glycoprotein was loaded into the nanoparticles during the hydration of hyaluronic acid-conjugated lipid films. A single dose vaccination of this glycoprotein-loaded nanoparticle was shown to provide a 128-fold higher antigen-specific IgG serum titer compared to that achieved with glycoprotein alone. The glycoprotein-loaded nanoparticle further protected $80 \%$ of the immunized mice from Ebola virus challenge, whereas soluble glycoprotein yielded only $10 \%$ protection.

Ebola virus spike glycoprotein was subcutaneously delivered using lipid nanoparticles with nickel elements [82] (Fig. 5). The lipid nanoparticles were composed of 1,2-dioleoyl-sn-glycero-3-phosphocholine, 1,2-dioleoyl-snglycero-3-phosphoethanolamine-N-[4-(p-maleimidophenyl) butyramide] sodium salt, and 1,2-dioleoyl-sn-glycero-3-[(N(5-amino-1-carboxypentyl) iminodiacetic acid)succinyl] nickel salt. For crosslinking of the viral glycoprotein with the lipid bilayer, the researchers used a poly-histidine tagged protein and linked the histidine tag to the nickel elements of the lipid bilayers. The interaction between the histidine tag of the viral antigen and the nickel of the lipid bilayer enabled the glycoprotein to be loaded without chemical crosslinking or conformational change. The glycoprotein loading efficiency was $32.8 \%$. Subcutaneous injection of the glycoprotein in the lipid nanoparticles increased the percentage of antigen-specific B cells in secondary lymph organs and yielded 5.8-fold more IFN- $\gamma$-expressing $\mathrm{T}$ cells in spleen compared to those in the group treated with soluble glycoprotein antigen alone.

Copolymer-based cationic nanoparticles were studied for delivery of DNA encoding glycoprotein of Ebola virus [83]. PLGA nanoparticles were coated with pol-l-lysine to form cationic nanoparticles, and the DNA vaccine was loaded onto the surface of these poly-1-lysine-coated cationic PLGA nanoparticles. The complexes of DNA with the cationic nanoparticles were further coated on the surfaces of a microneedle composed of polyvinyl alcohol and polyvinylpyrrolidone. Skin application of the polyplexed DNAcoated microneedle patch yielded higher antigen-specific IgG titers compared with intramuscular injection of naked DNA. Moreover, the microneedle-vaccinated group was able to neutralize $50 \%$ of glycoprotein-pseudovirions.

Overall, specific delivery systems have shown promises against various viruses such as SARS-CoV-2, MERS-CoV, Zika virus, and Ebola virus. In viral vaccines, the emerging new variants are critical issues. Currently, more studies have been done to formulate nucleic acid vaccines compared with protein vaccines. Nucleic acid vaccines may have advantage to cope with rapidly emerging variants of infectious viruses. In the cases of protein vaccines, studies on conservative domains of viruses would be important. The development of multi-valent vaccines which can induce immune responses for several strains of viruses would be a direction to purse in the future.

\section{Challenges and perspectives}

Although significant progress has been made in the nanotechnologies for delivering various viral vaccine antigens, several challenges remain to be addressed in future studies. In the cases of nucleic acid vaccine delivery, the degradation of nucleic acid antigens in lysosomes would be expected to lower the immunogenicity. Peptides or chemicals have been reported to facilitate the endosomal escape of lysosomal cargoes. For instance, KALA peptide (an amphiphilic cationic peptide) was conjugated to lipid nanoparticles to enhance the escape efficiency of delivered cargoes from endosomes to cytoplasm [84]. The antimalarial agent, chloroquine, has been reported to facilitate the endosomal escape of cholesterol-conjugated siRNA, which resulted in 6-fold higher target gene knockdown compared to that obtained with free cholesterol-conjugated siRNA [85]. More studies on the lysosome-escaping ability of new materials or co-delivery of nucleic acid vaccines with lysosome escapepromoting agents are expected to improve the efficacy of nucleic acid vaccine delivery systems.

The combination of nanovaccines with other adjuvant systems needs to be studied further. A few studies reported that enhanced immunogenicity was achieved by combining nanovaccines with commercial adjuvants [46], or codelivering nanovaccines with adjuvants in a nanomaterial. In cancer immunotherapy, the entrapment of various immune adjuvants (e.g., imiquimod) was found to enhance dendritic cells maturation and systemic immune responses [86]. The entrapment of adjuvants in the lipid bilayers of liposomes or the hydrophobic core parts of polymeric nanoparticles may be one way to improve the immune responses of codelivered vaccine antigens.

Most studies have focused on the development of immune responses and survival upon challenge. Antigen-specific serum IgG levels have been evaluated after administration of most delivery systems. When developing vaccines against viruses that infect through mucosal routes, researcher should monitor the induction of IgA in mucosal secretions. For more elaborate design and evaluation at the initial stage of nanomaterial development, mechanism studies should be fortified, such as by including studies on intracellular endocytosis pathways, intracellular trafficking, and possibly exocytosis. The MHC class I and II processing pathways of delivered antigens need to be studied. For nucleic acid vaccines, the secretion of expressed protein antigens and their uptake by adjacent antigen-presenting cells can boost MHC class II processing.

For clinical translation, the manufacturing process and physical stability of nanomaterial-based vaccines should be studied during the development phase [87]. Given the limitation of worldwide cold chains, the stability of vaccine 
candidates under humid and hot conditions should be studied. For lipid-based delivery systems, the oxidations of lipid components during storage can be a concern. In nanoparticle formulations, the precipitation and related size changes of nanoparticles would alter the efficacy and safety. In the final formulation, the use of excipients to protect the antigen and delivery components from various degrading stimuli, such as oxygen, light, and moisture should be studied.

In addition to monitoring the physical stability of vaccine formulations over time, the persistence of induced antibodies should be evaluated over prolonged periods during the development of vaccine delivery systems. Only a few existing studies have tested the persistence of antibodies after treatment with nanoformulation-based delivery systems [63]. Future studies should monitor how the dosing amount, frequency, and interval affects the induction and duration of antibody responses.

The choice of a proper administration route for vaccination is a critical factor in vaccine efficacy and successful vaccine development. To induce desirable vaccine efficacy, the vaccine should be transported from the administered site to suitable immune organs where the immune reaction should occur. As the types and extents of induced immune responses differ according to the vaccine administration site, careful considerations are necessary for vaccine development. To date, the majority of investigated delivery systems have been administered using intramuscular, subcutaneous, and intradermal injections.

Noninvasive forms of delivery systems need to be studied more in the future. A few studies have reported the skin delivery using microneedle patches. Noninvasive mucosal or topical delivery systems may have advantages over parenteral injection. For example, they can increase patient compliance by reducing pain and enabling administration in the home without needing a healthcare professional [88]. Such systems would also reduce disease transmission from needle-reuse, which has been a problem worldwide [89]. Mucosal vaccine delivery systems may face challenges, such as mucocilliary clearance and enzymatic degradation at mucosal surfaces [88], but these limitations could possibly be overcome by using mucosal vaccine formulations with muco-adhesive properties or applying specific administration devices.

In parallel with continued progress in developing and evaluating delivery systems, the rapid analysis of vaccine candidates could be important. Various technologies are needed to develop vaccines for rapid and efficient prevention of infectious diseases. One such technology would be the application of bioinformatics to analyze databases and provide information for rapid vaccine development [90]. When SARS-CoV-2 emerged as a new pathogen, there was not much specific information available. However, the accumulated coronavirus-related data stored in databases such as the existing Immune Epitope Data-based and Analysis Resource or Virus Pathogen Resource provided a great deal of information about the new pathogen. Bioinformatic studies revealed that there is significant structural homology between SARS-CoV-2 and SARS-CoV. Moreover, bioinformatics tools (e.g., BepiPred, DiscoTope, and TepiTool) enabled researchers to predict the sequences and tertiary structures of the relevant $\mathrm{B}$ cell and $\mathrm{T}$ cell epitopes. In this way, the application of bioinformatics in vaccine development will be a powerful tool to quickly and efficiently derive vaccine candidates when an unexpected infectious disease occurs in the future.

\section{Conclusions}

To prepare rapid countermeasures against a variety of unpredictable pathogens threatening humanity, future vaccines are expected to rely on nanoplatform technology for antigen delivery. It currently takes several years to develop a vaccine after the onset of an infectious disease, and thus, it is difficult to prevent the rapid spread of a disease like COVID-19 using the conventional vaccine development process. The versatile characteristics of nanotechnology will enable various strategies aimed at modulating the immune responses of vaccine antigens. Preventing enzymatic degradation and ensuring controlled release of antigens are key features of nanocarriers that can be rapidly applied to vaccine delivery. Nanocarrier delivery systems can also get the vaccine to the target site efficiently by enhancing the targeting of specific immune cells through the conjugation of receptor-specific ligand molecules. This active targeting will help transport the vaccine to specific organs and immune cells, and thereby facilitate antigen uptake. The pipelines for developing vaccine delivery systems that can generate potent immune responses can offer great potential for rapid development of new-generation vaccines.

Author contributions Dongyoon Kim and Yina Wu contributed to writing of original draft. Young Bong Kim contributed to conceptualization and supervision. Yu-Kyoung Oh contributed to supervision and editing.

Funding This research was supported by grants from the Basic Science Research Program through the National Research Foundation of Korea (NRF) funded by the Ministry of Science and ICT, Republic of Korea (NRF-2021R1A2B5B03002123; NRF-2018R1A5A2024425), and the Korean Health Technology R\&D Project (No. HI15C2842; HI18C2177), Ministry of Health \& Welfare, Republic of Korea.

\section{Declarations}

Ethics approval and consent to participate No animals were used in the present study.

Consent for publication The authors have read the final version and give their consents for the article to be published in Drug Delivery and Translational Research. 
Competing interests The authors declare that they have no conflict of interest.

\section{References}

1. Zhou Y, Hou Y, Shen J, Huang Y, Martin W, Cheng F. Networkbased drug repurposing for novel coronavirus 2019-nCoV/SARSCoV-2. Cell Discov. 2020;6:14.

2. Tay MZ, Poh CM, Rénia L, MacAry P, Ng L. The trinity of COVID-19: Immunity, inflammation and intervention. Nat Rev Immunol. 2020;20:363-74.

3. Fries CN, Curvino EJ, Chen JL, Permar SR, Fouda GG, Collier $\mathrm{JH}$. Advances in nanomaterial vaccine strategies to address infectious diseases impacting global health. Nat Nanotechnol. 2020. https://doi.org/10.1038/s41565-020-0739-9.

4. Minor PD. Live attenuated vaccines: Historical successes and current challenges. Virology. 2015;479-480:379-92.

5. Cabral MP, García P, Beceiro A, Rumbo C, Pérez A, Moscoso M, Bou G. Design of live attenuated bacterial vaccines based on D-glutamate auxotrophy. Nat Commun. 2017;8:15480.

6. Khalaj-Hedayati A, Chua CLL, Smooker P, Lee KW. Nanoparticles in influenza subunit vaccine development: Immunogenicity enhancement. Influenza Other Respir Viruses. 2020;14:92-101.

7. Bidet K, Ho V, Chu CW, Naim ANH, Thazin K, Chan KR, Low JGH, Choy MM, Wong LH, Sessions PF, Lee YH, Hibberd ML, Ooi EE, Fink K, Chen J. Mimicking immune signatures of flavivirus infection with targeted adjuvants improves dengue subunit vaccine immunogenicity. NPJ Vaccines. 2019;4:27.

8. Sautto GA, Kirchenbaum GA, Diotti RA, Criscuolo E, Ferrara F. Next generation vaccines for infectious diseases. J Immunol Res. 2019;2019:5890962.

9. Park KS, Bazzill JD, Son S, Nam J, Shin SW, Ochyl LJ, Stuckey JA, Meagher JL, Chang L, Song J, Montefiori DC, LaBranche CC, Smith JL, Xu J, Moon JJ. Lipid-based vaccine nanoparticles for induction of humoral immune responses against HIV-1 and SARS-CoV-2. J Control Release. 2020;330:529-39.

10. Kim J, ygeris Y, Gupta M, Sahay G. Self-assembled mRNA vaccines. Adv Drug Deliv Rev. 2021; 70:83-112.

11. Kwak JE, Kim YI, Park SJ, Yu MA, Kwon HI, Eo S, Kim TS, Seok J, Choi WS, Jeong JH, Lee H, Cho Y, Jin Ah, Kwon JA, Jeong M, Maslow JN, Kim YE, Jeon H, Kim KK, Shin EC, Song MS, Jung JU, Choi YK, Park SH. Development of a SFTSV DNA vaccine that confers complete protection against lethal infection in ferrets. Nat Commun. 2019;10:3836.

12. Pushparajah D, Jimenez S, Wong S, Alattas H, Nafissi N, Slavcev RA. Advances in gene-based vaccine platforms to address the COVID-19 pandemic. Adv Drug Deliv Rev. 2021;170:113-41.

13. Braathen R, Spång HCL1 Hinke DM, Blazevski J, Bobic S, Fossum E, Bogen B. A DNA vaccine that encodes an antigen-presenting cell-Specific heterodimeric protein protects against cancer and influenza. Mol Ther Methods Clin Dev. 2020;17:378-92.

14. Anderluzzi G, Schmidt ST, Cunliffe R, Woods S, Roberts CW, Veggi D, Ilaria Ferlenghi I, O'Hagan DT, Baudner $\mathrm{BC}$, Perrie Y. Rational design of adjuvants for subunit vaccines: The format of cationic adjuvants affects the induction of antigen-specific antibody responses. J Control Release. 2020;:S0168-3659(20):30647-57.

15. Qiao C, Liu J, Yang J, Li Y, Weng J, Shao Y, Zhang X. Enhanced non-inflammasome mediated immune responses by mannosylated zwitterionic-based cationic liposomes for HIV DNA vaccines. Biomaterials. 2016;85:1-17.

16. Seok HY, NohJY, Yong Lee DY, Kim SJ, Song CS, Kim YC. Effective humoral immune response from a H1N1 DNA vaccine delivered to the skin by microneedles coated with PLGA-based cationic nanoparticles. J Control Release. 2017;265:66-74.

17. Xu L, Liu Y, Chen Z, Li W, Liu Y, Wang L, Liu Y, Wu X, Yinglu Ji Y, Zhao Y, Ma L, Shao Y, Chen C. Surface-engineered gold nanorods: promising DNA vaccine adjuvant for HIV-1 treatment. Nano Lett. 2012;12:2003-12.

18. Tian Y, Wang H, Liu Y, Mao L, Chen W, Zhu Z, Liu W, Zheng W, Zhao Y, Kong D, Yang Z, Zhang W, Shao Y, Jiang X. A peptide-based nanofibrous hydrogel as a promising DNA nanovector for optimizing the efficacy of HIV vaccine. Nano Lett. 2014;14:1439-45.

19. Xu L, Liu Y, Chen Z, Li W, Liu Y, Wang L, Ma L, Shao Y, Yuliang Zhao Y, Chen C. Morphologically virus-like fullerenol nanoparticles act as the dual-functional nanoadjuvant for HIV-1 vaccine. Adv Mater. 2013;25:5928-36.

20. Pardi N, Parkhouse K, Kirkpatrick E, McMahon M, Zost SJ, Mui BL, Tam YK, Karikó K, Barbosa CJ, Madden TD, Hope MJ, Krammer F, Hensley SE, Weissman D. Nucleoside-modified mRNA immunization elicits influenza virus hemagglutinin stalk-specific antibodies. Nat Commun. 2018;9:3361.

21. Goswami R, Chatzikleanthous D, Lou G, Giusti F, Alessandra Bonci A, Taccone M, Brazzoli M, Gallorini S, Ferlenghi I, Berti F, O'Hagan DT, Pergola C, Baudner BC, Adamo R. Mannosylation of LNP results in improved potency for self-amplifying RNA (SAM) vaccines. ACS Infect Dis. 2019;5:1546-58.

22. Wilson DS, Hirosue S, Raczy MM, Ramirez LB, Jeanbart L, Wang R, Kwissa M, Franetich JF, Broggi MAS, Diaceri G, Thermes XQ, Mazier D, Swartz MA, Hubbell JA. Antigens reversibly conjugated to a polymeric glyco-adjuvant induce protective humoral and cellular immunity. Nat Mater. 2019;18:175-85.

23. Yang R, Xu J, Xu L, Sun X, Chen Q, Zhao Y, Peng R, Liu Z. Cancer cell membrane-coated adjuvant nanoparticles with mannose modification for effective anticancer vaccination. ACS Nano. 2018;12:5121-9.

24. Zhang C, Shi G, Zhang J, Song H, Niu J, Shi S, Pingsheng Huang P, Wang Y, Wang W, Li C, Kong D. Targeted antigen delivery to dendritic cell via functionalized alginate nanoparticles for cancer immunotherapy. J Control Release. 2017;256:170-81.

25. Blakney AK, McKay PF, Yus BI, Y, Shattock R. Inside out: optimization of lipid nanoparticle formulations for exterior complexation and in vivo delivery of saRNA. Gene Ther.2019;26:363-72.

26. Pardi N, Secreto AJ, Shan X, Debonera F, Glover J, Yi Y, Muramatsu H, Ni H, Mui BL, Tam YK, Shaheen F, Collman RG, Karikó K, Desnoyers GAD, Dadden TD, Hope MJ, Weissman D. Administration of nucleoside-modified mRNA encoding broadly neutralizing antibody protects humanized mice from HIV-1 challenge. Nat Commun. 2017;8:14630.

27. Chahal JS, Khan OF, Cooper CL, McPartlan JS, K Tsosie JK, Tilley LD, Sidik SM, Lourido S, Langer R, Bavari S, Ploegh H, Anderson DG. Dendrimer-RNA nanoparticles generate protective immunity against lethal Ebola, H1N1 influenza, and Toxoplasma gondii challenges with a single dose. Proc Natl Acad Sci U S A. 2016;113:E4133-42.

28. Blakney AK, Zhu Y, McKay PF, Bouton CR, Yeow J, Tang J, Hu K, Samnuan K, Grigsby CL, Shattock RJ, Stevens MM. Big Is beautiful: Enhanced saRNA delivery and immunogenicity by a higher molecular weight, bioreducible, cationic polymer. ACS Nano. 2020;14:5711-27.

29. McCullough KC, Bassi I, Milona P, Sute rR, Harwood LT, Englezou P, Démoulins T, Ruggli N. Self-replicating Replicon-RNA delivery to dendritic cells by chitosan-nanoparticles for translation in vitro and in vivo. Mol Ther Nucleic Acids. 2014;3:e173.

30. Zhao M, Li M, Zhang Z, Gong T, Sun X. Induction of HIV-1 gag specific immune responses by cationic micelles mediated delivery of gag mRNA. Drug Deliv. 2016;23:2596-607. 
31. Coolen AL, Lacroix C, Gouy PM, Delaune , Monge C, Exposito JY, Verrier B. Poly(lactic acid) nanoparticles and cell-penetrating peptide potentiate mRNA-based vaccine expression in dendritic cells triggering their activation. Biomaterials. 2019;195:23-37.

32. Elmowafy EM, Tiboni M, Mahmoud E, Soliman ME. Biocompatibility, biodegradation and biomedical applications of poly(lactic acid)/poly(lactic-co-glycolic acid) micro and nanoparticles. J Pharm Investig. 2019;49:347-80.

33. Rességuier J, Delaune E, Coolen AL, Levraud JP, Boudinot PB, Le Guellec DL, Verrier B. Specific and efficient uptake of surfactant-free poly(lactic acid) nanovaccine vehicles by mucosal dendritic cells in adult zebrafish after bath immersion. Front Immunol. 2017;8:190.

34. Hollingshead S, Jongerius I, Exley RM, Johnson S, Lea SM, Tang CM. Structure-based design of chimeric antigens for multivalent protein vaccines. Nat Commun. 2018;9:1051.

35. Fan Y, Moon J. Particulate delivery systems for vaccination against bioterrorism agents and emerging infectious pathogens. Wiley Interdiscip Rev Nanomed Nanobiotechnol. 2017;9:10.

36. Knight FC, Gilchuk P, Kumar A, Becker KW, Sevimli S, Jacobson ME, Suryadevara N, Bishop LW, Boyd KL, JEC, Joyce S, Wilson JT. Mucosal immunization with a $\mathrm{pH}$-responsive nanoparticle vaccine induces protective $\mathrm{CD} 8+$ lung-resident memory T Cells. ACS Nano. 2019;13:10939-60.

37. Liu Q, Chen X, Jia J, Lu T, Yang T, Lianyan WL. Potential hepatitis $\mathrm{B}$ vaccine formulation prepared by uniform-sized lipid hybrid PLA microparticles with adsorbed hepatitis B surface antigen. Mol Pharm. 2018;15:5227-35.

38. Qi M, Zhang XE, Sun X, Zhang X, Yao Y, Liu Z, Chen Z, Li W, Zhang Z, Chen J, Cui Z. Intranasal nanovaccine confers homo- and hetero-subtypic influenza protection. Small. 2018;14:e1703207.

39. Deng L, Mohan T, Chang T, Gonzalez GX, Wang Y, Kwon YM, Kang SM, Compans RW, Champion JA2, Wang BZ. Doublelayered protein nanoparticles induce broad protection against divergent influenza A viruses. Nat Commun. 2018;9(1):359.

40. Montemiglio LC1, Testi C, Ceci P, Falvo E, Pitea M, Savino C, Arcovito A, Peruzzi G, Baiocco P, Mancia F, Boffi A, Georges A, Vallone B. Cryo-EM structure of the human ferritin-transferrin receptor 1 complex. Nat Commun. 2019;10:1121.

41. Liang M, Fan K, Zhou M, DuanD , Zheng J, Yang D, Feng J, Yan X. H-ferritin-nanocaged doxorubicin nanoparticles specifically target and kill tumors with a single-dose injection. Proc Natl Acad Sci USA. 2014;111:14900-5.

42. Macone A, Masciarelli S, Palombarini F, Quaglio D, Alberto Boffi A, Trabuco MC, Baiocco P, Fazi F, Bonamore A. Ferritin nanovehicle for targeted delivery of cytochrome $\mathrm{C}$ to cancer cells. Sci Rep. 2019;9:11749.

43. Serradell MC, Rupil LL, Martino RA, Prucca C, Carranza PG, Saura, Fernández EA, Gargantini PR, Tenaglia AH, Petiti JP, Tonelli RR, Vizcaino NR, Echenique J, Berod L, Piaggio E, Bellier B, Sparwasser T, Klatzmann D, Luján HD. Efficient oral vaccination by bioengineering virus-like particles with protozoan surface proteins. Nat Commun. 2019;10:361.

44. Gao Y, Wijewardhana C, Mann JFS. Virus-like particle, liposome, and polymeric particle-based vaccines against HIV-1. Front Immunol. 2018;9:345.

45. Sharma J, Shepardson K, Johns LL, Wellham J, Avera J, Schwarz B, Rynda-Apple A, Douglas T. A self-adjuvanted, modular, antigenic VLP for rapid response to influenza virus variability. ACS Appl Mater Interfaces. 2020;12:18211-24.

46. Müller H, Fehling SK, Dorna J, Urbanowicz RA, Oestereich L, Krebs Y, Kolesnikova L, Schauflinger M, Krähling V, Magassouba N, Calvet EF 6, K Ball JK, Kaufmann A, Bauer SS, Becker $\mathrm{S}$, Messling V, Tomas Strecker T. Adjuvant formulated virus-like particles expressing native-like forms of the Lassa virus envelope surface glycoprotein are immunogenic and induce antibodies with broadly neutralizing activity. NPJ Vaccines. 2020;5:71.

47. Robinson JE, Hastie KM, Cross RW, Yenni RE, Elliott DH, Rouelle JA, Kannadka CB, Smira AA, Garry CE, Bradley BT, Yu H, Shaffer JG, Boisen ML, Hartnett JN, Zandonatti MA, Rowland MM, Heinrich ML, Sobrido LM, Cheng B, Torre J, Andersen K, Goba A, Momoh M, Fullah M, Gbakie M, Kanneh L, Koroma V, Fonnie R, Jalloh S, Kargbo B, Vandi M, Gbetuwa M, Ikponmwosa O, Asogun D, Okokhere P, Follarin O, Schieffelin J, Pitts K, Geisbert J, Kulakoski P, Wilson R, Happi C, Sabeti P, Gevao S, Khan H, Grant D, Geisbert T, Saphire E, Branco L, Garry R. Most neutralizing human monoclonal antibodies target novel epitopes requiring both Lassa virus glycoprotein subunits. Nat Commun. 2016;7:11544.

48. Makarkov AI, Golizeh M, Lancheros ER, Gopal A, Cancelas INC, Sabrina Chierzi S, Pillet S, Charland N, Ward BJ. Plantderived virus-like particle vaccines drive cross-presentation of influenza A hemagglutinin peptides by human monocyte-derived macrophages. NPJ Vaccines. 2019;4:17.

49. Guzman DS, Guen PL, Villeret B, Sola N, Borgne RL, Guyard A, Kemmel A, Verdugo IG. Silver nanoparticle-adjuvanted vaccine protects against lethal influenza infection through inducing BALT and IgA-mediated mucosal immunity. Biomaterials. 2019;217:119308.

50. Chen HW, Huang CY, Lin SY, Fang ZS, Hsu CH, Lin JC, Chen YI, Yao BY, Hu CM. Synthetic virus-like particles prepared via protein corona formation enable effective vaccination in an avian model of coronavirus infection. Biomaterials. 2016;106:111-8.

51. Chakraborty B, Pal R, Ali M, Ghosh K, Sengupta M. Immunomodulatory properties of silver nanoparticles contribute to anticancer strategy for murine fibrosarcoma. Cell Mol Immunol. 2016;13:191-205.

52. DuránN, Silveira C, Durán M, Martinez DST. Silver nanoparticle protein corona and toxicity: a mini-review. J Nanobiotechnology. 2015;13:55.

53. Ma W, Saccardo A, Roccatano D, Mensah DA, Alkaseem M, Jewkes M, Nezza F, Baron M, Soloviev M, Ferrari E. Modular assembly of proteins on nanoparticles. Nat Commun. 2018;9:1489.

54. Longmire M, Choyke PL, Kobayashi H, Clearance properties of nano-sized particles and molecules as imaging agents: considerations and caveats. Nanomedicine (Lond).2008;3:703-17.

55. Zhou P, Yang XL, Wang XG, Hu B, Zhang L, Zhang W, Si HR, Zhu Y, Li B, Huang CL, Chen HD, Chen J, Guo H, Jiang RD, , Chen Y, ShenX, Wang X, Chen Q, Deng F, Liu L, Yan B, Xiao G, Shi Z. A pneumonia outbreak associated with a new coronavirus of probable bat origin. Nature. 2020;579:270-3.

56. Yu J, Chai P, Ge S, Fan X. Recent understandings toward coronavirus disease 2019 (COVID-19): From bench to bedside. Front Cell Dev Biol. 2020;8:476.

57. Bert N, Tan A, Kunasegaran K, Hafezi M, Chia A, Chng M, Lin M, Tan N, Linster M, Chia W, Chen M, Wang L, Ooi E, Low J, Yee-Joo Tan Y, Bertoletti A. SARS-CoV-2-specific T cell immunity in cases of COVID-19 and SARS, and uninfected controls. Nature. 2020;584:457-62.

58. Mousavizadeh L, Ghasemi S. Genotype and phenotype of COVID19: Their roles in pathogenesis. J Microbiol Immunol Infect. 2020. https://doi.org/10.1016/j.jmii.2020.03.022.

59. Petrosillo N, Viceconte G, Ergonul O, Ippolito G, Petersen E. COVID-19, SARS and MERS: Are they closely related? Clin Microbiol Infect. 2020;26:729-34.

60. Corbett KS, Edwards DK, Leist SR, Abiona OM, Barnum SB, Gillespie RA, Himansu S, Schäfer A, Ziwawo CT, DiPiazza AT, Dinnon KH, S Elbashir SM, Shaw CA, Woods A, Fritch EJ, Martinez DR, Bock KW, = Minai M, Nagata BM, BHutchinson GB, Wu K, Henry C , Ma L, Renzi I, Alvarado G, Nason M, Ruckwardt T, McLellan J, Denison M, Moore I, Morabito K, Mascola J, Baric RS, 
Carfi A, Graham BS. SARS-CoV-2 mRNA vaccine design enabled by prototype pathogen preparedness. Nature. 2020;586:567-71.

61. Zhang NN, Li XF, Deng YQ, Zhao H, HuangYJ, Yang G, Huang WJ, Gao P, Zhou C, Zhang RR, Guo Y, Sun SH, Fan H, Zu SL, Chen Q, He Q, Cao, Huang XY, Qiu HY, Nie JH, Jiang Y, Yan HY, Ye Q, Zhong X, Xue XL, Zha ZY, Zhou D, Yang X, Chun Wang YC, Ying $\mathrm{B}$, Qin CF. A thermostable mRNA vaccine against COVID-19. Cell. 2020;182:1271-83.

62. McKay PF, Hu K, Blakney AK, Samnuan K, CBrown JC, Penn R, Zhou J, Polra K, Lin PJC, Barbosa C, Tam YK, Barclay WS, Shattock RJ. Self-amplifying RNA SARS-CoV-2 lipid nanoparticle vaccine candidate induces high neutralizing antibody titers in mice. Nat Commun. 2020;11:3523.

63. Erasmus JH, Khandhar AP, O'Connor MA, Walls AC, Hemann EA, Murapa P, Archer J, Leventhal S, Fuller JT, Lewis TB, Draves KE, Randall S, Guerriero KA, Duthie MS, Carter D, Reed SG, Hawman DW, Feldmann H, Berglund P, Fuller DH. An Alphavirus-derived replicon RNA vaccine induces SARS-CoV-2 neutralizing antibody and $\mathrm{T}$ cell responses in mice and nonhuman primates. Sci Transl Med. 2020;12:eabc9396.

64. Cui J, Li F, Shi ZL. Origin and evolution of pathogenic coronaviruses. Nat Rev Microbiol. 2019;17:181-92.

65. Xu J, Jia W, Wang P, Zhang S, Shi X, Wang X, Zhang L. Antibodies and vaccines against Middle East respiratory syndrome coronavirus. Emerg Microbes Infect. 2019;8:841-56.

66. Farooq HZ, Davies E, Ahmad S, Machin N, Hesketh L, Guiver M, Turner AJ. Middle East respiratory syndrome coronavirus (MERS$\mathrm{CoV}$ ) - Surveillance and testing in North England from, 2012 to 2019. Int J Infect Dis. 2020;93:237-44.

67. Lin LCW, Huang CY, Yao, Lin JC, Agrawal A, Algaissi A, Peng BH, Liu YH, Huang PH, Juang RH, Chang YC, Tseng CT, Chen HW, Jack Hu CMJ. Viromimetic STING agonist-loaded hollow polymeric nanoparticles for safe and effective vaccination against Middle East Respiratory Syndrome Coronavirus. Adv Funct Mater. 2019;29:1807616.

68. Kim YS, Son A, Kim J, Kwon SB, Kim MH, Kim P, Jieun J, Byun YH, Sung J, Lee J, Yu JE, Park C, Kim YS, Hyuk Cho NH, Chang J, Seong BL. Chaperna-mediated assembly of ferritin-based Middle East Respiratory Syndrome-Coronavirus nanoparticles. Front Immunol. 2018;9:1093.

69. Liu ZY, ShiWF, Qin CF. The evolution of Zika virus from Asia to the Americas. Nat Rev Microbiol. 2019;17:131-139.

70. Dawes BE, Smalley CA, Tiner BL, Beasley DW, Milligan GN, Reece LM, Hombach J, Barrett AD. Research and development of Zika virus vaccines. NPJ Vaccines. 2016;1:16007.

71. Lowe R, Barcellos C, Brasil P, Cruz OG, Honório NA, Kuper H, Carvalho MS. The Zika virus epidemic in Brazil: From discovery to future implications. Int J Environ Res Public Health. 2018;15:96.

72. Teixeira MG, Costa M, Oliveira W, Nunes ML, Rodrigues LC. The epidemic of Zika virus-related microcephaly in Brazil: Detection, control, etiology, and future scenarios. Am J Public Health. 2016;106:601-5.

73. Poland GA, Ovsyannikova IG, Kennedy RB. Zika vaccine development: Current status. Mayo Clin Proc. 2019;94:2572-86.

74. Pardi N, Hogan MJ, Pelc RS, Muramatsu H, Andersen H, DeMaso CR, Dowd KA, Sutherland LL, Robert Parks, Wagner W3, Granados A, Greenhouse J, Walker M, Willis E, Gregory D Sempowski GD, Mui BL, Tam YK, Huang YJ, Vanlandingham D, M Holmes VM, Balachandran H, Sahu S, Lifton M, Higgs S, Hensley SE, Madden TD, Hope MJ, Karikó K, Santra S, Barney S Graham BS, Lewis MG, Pierson TC2, Haynes BF, Weissman D. Zika virus protection by a single low-dose nucleoside-modified mRNA vaccination. Nature. 2017;543:248-51.
75. Richner JM, Himansu S, Dowd KA, Butler SL, Salazar V, Fox JM, Julander JG, Tang WW, Shresta S, Pierson TC, Ciaramella G, Diamond MS. Modified mRNA vaccines protect against Zika virus infection. Cell. 2017;169:176.

76. Chahal JS, Tao Fang T, Woodham AW, Khan OF, Ling J, Anderson DG, Ploegh HL. An RNA nanoparticle vaccine against Zika virus elicits antibody and CD8+ T cell responses in a mouse model. Sci Rep. 2017;7:252.

77. Hraber P, BradfuteS, Clarke E, Ye C, Pitard B. Amphiphilic block copolymer delivery of a DNA vaccine against Zika virus. Vaccine. 2018;36:6911-17.

78. Jacob ST, Crozier I, Fischer WA, Hewlett A, Kraft CS, Soka MJ, Griffiths A, Bollinger L, Kuhn JH. Ebola virus disease. Nat Rev Dis Primers. 2020;6:13.

79. Hoenen T, Groseth A, Heinz FH. Therapeutic strategies to target the Ebola virus life cycle. Nat Rev Microbiol. 2019;17:593-606.

80. Feldmann H, Jones S, Klenk HD, Schnittler HJ. Ebola virus: From discovery to vaccine. Nat Rev Immunol. 2003;3:677-85.

81. Fan Y, M Stronsky SM, Xu Y, Steffens JT, Tongeren SA, Erwin A, Cooper CL, Moon JJ. Multilamellar vaccine particle elicits potent immune activation with protein antigens and protects mice against Ebola virus infection. ACS Nano. 2019;13:11087-96.

82. Bazzill JD, Stronsky SM, Kalinyak LC, Ochyl LJ, Steffens JT, Tongeren SA, Cooper CL, Moon JJ. Vaccine nanoparticles displaying recombinant Ebola virus glycoprotein for induction of potent antibody and polyfunctional $\mathrm{T}$ cell responses. Nanomedicine. 2019;18:414-25.

83. Yang HW, Ye L, Guo XD, Yang C, Compans RW, Prausnitz MR. Ebola vaccination using a DNA vaccine coated on PLGA-PLL/ $\gamma$ PGA nanoparticles administered using a microneedle patch. Adv Healthc Mater. 2017;6:1600750.

84. Miura N, Shaheen SM, Akita H, Nakamura T, Harashima H. A KALA-modified lipid nanoparticle containing CpG-free plasmid DNA as a potential DNA vaccine carrier for antigen presentation and as an immune-stimulative adjuvant. Nucleic Acids Res. 2015;43:1317-31.

85. Rietz HD, Hedlund H, Wilhelmson S, Nordenfelt P, Wittrup A. Imaging small molecule-induced endosomal escape of siRNA. Nat Commun. 2020;11:1809.

86. Le QV, Suh J, Choi JJ, Park GT, Lee JW, Shim G, Oh YK. In situ nanoadjuvant-assembled tumor vaccine for preventing long-term recurrence. ACS Nano. 2019;13:7442-62.

87. G Dacoba T, Ruiz-Gatón L, Benito A, Klein M, Dupin S, Luo M, Menta M, Teijeiro-Osorio D, Loinaz I, Alonso MJ, Crecente-Campo $\mathrm{J}$. Technological challenges in the preclinical development of an HIV nanovaccine candidate. Drug Deliv Transl Res. 2020; 10: 621-34.

88. Shakya AK, Chowdhury MYE, Tao W, Gill HS. Mucosal vaccine delivery: Current state and a pediatric perspective. J Control Release. 2016;240:394-413.

89. Singh B, Sushila Maharjan S, Princy Sindurakar P, Ki-Hyun Cho KH, Yun-Jaie Choi YJ, Chong-Su Cho CS. Needle-free immunization with chitosan-based systems. Int J Mol Sci. 2018;19:3639.

90. Grifoni A, Sidney J, Zhang Y, Scheuermann RH, Peters B, Sette A. A sequence homology and bioinformatic approach can predict candidate targets for immune responses to SARS-CoV-2. Cell Host Microbe. 2020;27:671-80.

Publisher's Note Springer Nature remains neutral with regard to jurisdictional claims in published maps and institutional affiliations. 